R. Marsh $\cdot$ A. Yool $\cdot$ T. M. Lenton · M. Y. Gulamali

N. R. Edwards · J. G. Shepherd · M. Krznaric

S. Newhouse $\cdot$ S. J. Cox

\title{
Bistability of the thermohaline circulation identified through comprehensive 2-parameter sweeps of an efficient climate model
}

Received: 27 January 2004 / Accepted: 30 August 2004 / Published online: 9 November 2004

(C) Springer-Verlag 2004

\begin{abstract}
The effect of changes in zonal and meridional atmospheric moisture transports on Atlantic overturning is investigated. Zonal transports are considered in terms of net moisture export from the Atlantic sector. Meridional transports are related to the vigour of the global hydrological cycle. The equilibrium thermohaline circulation (THC) simulated with an efficient climate model is strongly dependent on two key parameters that control these transports: an anomaly in the specified Atlantic-Pacific moisture flux $\left(\Delta F_{a}\right)$ and atmospheric moisture diffusivity $\left(K_{q}\right)$. In a large ensemble of spinup experiments, the values of $\Delta F_{a}$ and $K_{q}$ are varied by small increments across wide ranges, to identify sharp transitions of equilibrium THC strength in a 2-parameter space (between Conveyor "On" and "Off" states). Final states from this ensemble of simulations are then used as the initial states for further such ensembles. Large differences in THC strength between ensembles, for identical combinations of $\Delta F_{a}$ and $K_{q}$, reveal the coexistence of two stable THC states (Conveyor "On" and
\end{abstract}

R. Marsh · A. Yool $(\bowtie) \cdot$ J. G. Shepherd

Southampton Oceanography Centre, Southampton, UK

E-mail: axy@soc.soton.ac.uk

Tel.: + 44-23-80596339

Fax: + 44-23-80596247

T. M. Lenton

Centre for Ecology and Hydrology, Edinburgh, UK

Present address: T. M. Lenton

School of Environmental Sciences, University of East Anglia, Norwich, UK

M. Y. Gulamali · M. Krznaric $\cdot$ S. Newhouse London e-Science Centre, Imperial College, London, UK

N. R. Edwards

Physics Institute, University of Bern, Bern, Switzerland

S. J. Cox

School of Engineering Sciences, University of Southampton, Southampton, UK
"Off") - i.e. a bistable regime. In further sensitivity experiments, the model is forced with small, temporary freshwater perturbations to the mid-latitude North Atlantic, to establish the minimum perturbation necessary for irreversible THC collapse in this bistable regime. A threshold is identified in terms of the forcing duration required. The model THC, in a "Conveyor On" state, irreversibly collapses to a "Conveyor Off" state under additional freshwater forcing of just $0.1 \mathrm{~Sv}$ applied for around 100 years. The irreversible collapse is primarily due to a positive feedback associated with suppressed convection and reduced surface heat loss in the sinking region. Increased atmosphere-to-ocean freshwater flux, under a collapsed Conveyor, plays a secondary role.

\section{Introduction}

Theoretical and idealized model studies have demonstrated that the thermohaline circulation (THC) can exhibit multiple equilibria (Wang and Birchfield 1992; Lenderinck and Haarsma 1994; Rahmstorf 1994, 1995a). Two such equilibria are "On" and "Off" states of the "Conveyor Belt" mode of inter-hemispheric Atlantic overturning. If stable "On" and "Off" states of the Conveyor can exist under the same climate, the THC is considered to be bistable (Rahmstorf 2000). Such bistability raises the possibility of an irreversible transition between "On" and "Off" states under small perturbations in surface buoyancy flux. In particular, the presentday Conveyor "On" mode is sensitive to surface freshwater fluxes. Pioneering sensitivity experiments with an ocean general circulation model (GCM) coupled to a simple energy-balance atmosphere predicted that, as freshwater flux is artificially increased in the key area of Atlantic convection, the THC weakens and eventually collapses (Rahmstorf 1995b, 1996). 
In a range of ocean and climate models (mostly, but not exclusively, simple), a freshwater flux threshold for THC collapse is found to lie between 0 and $0.15 \mathrm{~Sv}$ $\left(1 \mathrm{~Sv}=10^{6} \mathrm{~m}^{3} \mathrm{~s}^{-1}\right)$. This is the same approximate range over which the THC is bistable (Rahmstorf 2000). The implication is that the present-day Conveyor may be vulnerable to a temporary, strong anomaly in surface freshwater flux. However, in recent standardised experiments with coupled GCMs, where an extreme $1 \mathrm{~Sv}$ "hosing" is specified for 100 years, the THC response is strongly model-dependent: the GFDL and UVic models suffer a collapse that shows no sign of recovery after several centuries (i.e. may be irreversible), but the collapsed THC of the HadCM3 model does recover within the same timeframe (Stouffer et al. 2004). The latest generation of GCMs suggest less of a potential to collapse, and none of the IPCC models predict it for the 21st century (Cubasch et al. 2001). However, under greenhouse gas (GHG) forcing, the THC does weaken in most GCMs, and the limitations of current models mean the possibility of collapse cannot be completely discounted.

In the IPCC experiments, THC weakening is mostly attributed to high-latitude warming, but a stronger hydrological cycle also contributes. The hydrological cycle is expected to intensify under rising $\mathrm{CO}_{2}$ and global warming (e.g. Yang et al. 2003), and evidence for intensification of the Atlantic hydrological cycle in recent decades is starting to emerge (Curry et al. 2003). While a more intense hydrological cycle will lead to stronger poleward moisture transport and possibly a weaker THC, an important factor in stabilising the THC is increased freshwater export from the Atlantic to the Pacific in a greenhouse-warmed world. Atmospheric moisture exchange between Atlantic and Pacific basins, especially at low latitudes, is believed to play a crucial role in THC stability (e.g. Thorpe et al. 2001). Schmittner et al. (2000) find that tropical Atlantic vapour export to the Pacific is enhanced during El Niño, with the difference between La Niña and El Niño years on the order of $0.1 \mathrm{~Sv}$. Evidence in support of this mechanism is the co-variation, over recent decades, of Pacific warming with enhanced evaporation and rising salinity in the tropical Atlantic (Latif 2001). Indeed, this mechanism appears to explain THC stability under rising $\mathrm{CO}_{2}$ in ECHAM4/OPYC, the most stable of the nine IPCC models (see Cubasch et al. 2001). Enhanced Atlantic-to-Pacific moisture exchange South of $45^{\circ} \mathrm{N}$ compensates the THC-destabilizing effects of higher latitude warming and freshening. By year 2100 in the model, anomalous net freshwater fluxes in the Atlantic zones $30^{\circ} \mathrm{S}-45^{\circ} \mathrm{N}$ and $45-90^{\circ} \mathrm{N}$ reach values of around -0.25 and $+0.10 \mathrm{~Sv}$, respectively (Latif et al. 2000). A similar mechanism has been identified in HadCM3 (Thorpe et al. 2001).

Overall then, climate models suggest that a combination of climate change and natural variability could either increase or decrease net freshwater flux in the Atlantic sector to an extent that may have consequences for the THC. The Atlantic THC response to a transient change in freshwater forcing may reveal the existence of multiple equilibria, each associated with a different pattern of convection (Lenderinck and Haarsma 1994; Rahmstorf 1995a). Using a box model of the climate system, Wang and Birchfield (1992) demonstrated multiple equilibria of NADW formation and the THC under different combinations of intra-basin (low to high latitudes) and inter-basin (Atlantic to Pacific) atmospheric moisture transport. However, while they are extremely useful tools, box models lack the dimensionality and dynamics necessary for reaching definitive conclusions. On the other hand, more complex climate models subjected to varying freshwater flux (e.g. Rahmstorf 1995a) and $\mathrm{CO}_{2}$ rise (e.g. Latif et al. 2000) are computationally too slow for a comprehensive study of THC stability.

Here, we systematically investigate the relative importance for THC stability of intra-basin and interbasin moisture transports in a climate model of intermediate complexity. We present results of large ensembles in which the model is integrated to near-equilibrium for many combinations of two key parameters:

- an atmospheric moisture diffusivity-principally controlling the strength of meridional (intra-basin) moisture transports

- an explicit moisture flux that represents anomalies in zonal (inter-basin) atmospheric moisture transport from the Atlantic to the Pacific.

The model is computationally efficient, and the THC can be spun up to equilibrium in just a few hours on a single processor of a desktop computer. Facilitating this study is the application of novel computing techniques, allowing us to complete extremely large ensembles of independent simulations (amounting to a combined model integration time of 42 million years) within a reasonable period of time. We are, therefore, able to effectively "sweep" and map the 2-parameter space, comprehensively establishing regions where alternative steady states and multiple equilibria of the model THC may occur.

The paper is arranged as follows. We provide a brief model description in Sect. 2, including details of the novel computing environment. Section 3 outlines our experimental design, Sect. 4 reports the experimental results, and discussion follows in Sect. 5.

\section{Model}

We use a new efficient climate model, C-GOLDSTEIN, which features a reduced physics (frictional geostrophic) 3-D ocean model coupled to a 2-D energy-moisture balance model (EMBM) of the atmosphere and a dynamicthermodynamic sea ice model. The ocean model, GOLDSTEIN, is as described in Edwards and Shepherd (2002), but at doubled resolution and configured in realistic global geometry. In addition, GOLDSTEIN now includes isoneutral and eddy-induced mixing scheme and spatially variable drag. The EMBM and sea ice model are based on components described in Weaver et al. (2001). 
Table 1 Key model parameters

\begin{tabular}{ll}
\hline Parameter & $\begin{array}{l}\text { Default value } \\
\text { (used throughout present study) }\end{array}$ \\
\hline Ocean isopycnal diffusivity & $2,000 \mathrm{~m}^{2} \mathrm{~s}^{-1}$ \\
Ocean diapycnal diffusivity & $10^{-5} \mathrm{~m}^{2} \mathrm{~s}^{-1}$ \\
Ocean drag & 2.5 days $^{-1}$ \\
Ocean wind stress scale & 2.0 \\
Sea-ice diffusivity & $2,000 \mathrm{~m}^{2} \mathrm{~s}^{-1}$ \\
EMBM heat diffusivity & $8,111,000 \mathrm{~m}^{2} \mathrm{~s}^{-1}$ \\
EMBM heat advection ratio & 0.1111 (zonally) \\
EMBM moisture advection ratio & 0.2626 \\
\hline
\end{tabular}

See Edwards and Marsh (2004) for a discussion of each parameterisation. (Heat diffusivity in this study has a sinusoidal form similar to that obtained by setting $s_{d}=0.1, l_{d}=1$ in the notation of Edwards and Marsh.)

We use a non-seasonal version of C-GOLDSTEIN, as described in Annan et al. (2004). Work is also in progress to couple C-GOLDSTEIN to models of the land surface, ice sheets, sediments and the global carbon cycle (under the GENIE project—see http://www.genie.ac.uk). The result will be a suite of new earth system models of intermediate complexity (EMICs) which will be suitable for long-term modelling of past, present and future climate dynamics. The present study examines THC stability in the present atmosphere-ocean-sea-ice configuration.

Edwards and Marsh (2004) have carried out a validation exercise with C-GOLDSTEIN, in which ten key parameters were altered both individually and in combination. Based in part on the results of that exercise, only two of these ten parameters are varied in the present study (see below). Table 1 lists the values of the remaining parameters, which were fixed throughout the following experiments. With this combination of parameters, we obtain a reasonable present-day climate-see Edwards and Marsh (2004).

The EMBM of C-GOLDSTEIN provides a simplified closure for heat and moisture fluxes. Outgoing longwave radiation is calculated by a polynomial function of atmospheric temperature and specific humidity. Atmospheric moisture transport is represented by a combination of advection and diffusion (plus area-limited flux adjustment — see below). Two key parameters dominate

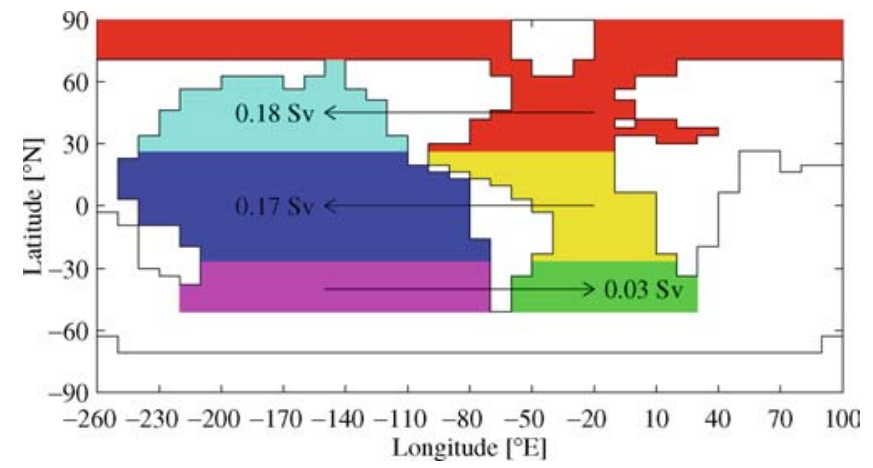

Fig. 1 The three zones where $F_{a}$ is applied, indicating default values atmospheric moisture transport that is of relevance for the THC:

1. $F_{a}$ : This adjusts zonal moisture transport from the Atlantic to the Pacific, by adding/subtracting anomalies to the surface freshwater flux in selected ocean regions (see Fig. 1). Without this adjustment, the model transports an unrealistically small quantity of freshwater (typically about $0.03 \mathrm{~Sv}$ ) from the Atlantic to the Pacific, and fails to reproduce the observed salinity difference between the basins, with the result that the THC is dominated by southern sinking. This is in contrast to the UVic model of Weaver et al. (2001), which includes essentially the same EMBM, but simulates a Conveyor mode THC with no such adjustment. This model difference may be partly due to the rather weak wind-driven circulation of CGOLDSTEIN (due to low resolution and the necessary high friction coefficient), compared to that in the primitive equation ocean component of the UVic model. The horizontal gyre circulation plays an important role in advecting high salinity water to the sinking region (e.g. Delworth et al. 1993). Additionally, the coarsely resolved bottom topography of CGOLDSTEIN may restrict deep water formation at high latitudes in the North Atlantic. The default value of $F_{a}$ in the model is $0.32 \mathrm{~Sv}$; the value deduced from observations by Oort (1983), distributed meridionally into three zones as in that study. To this default value, we add additional anomalies, $\Delta F_{a}$, which are partitioned between the three zones in proportion to default component values. We thus vary $F_{a}$ across a range of values (from near zero to near doubling) which encompass both the uncertainty suggested by data and the range of changes predicted by climate models under higher/rising atmospheric $\mathrm{CO}_{2}$ (e.g. Zaucker and Broecker 1992; Latif et al. 2000).

2. $K_{q}$ : This is atmospheric moisture diffusivity, which parameterises the eddy-diffusive component of moisture transport. The principal orientation of this diffusive transport is meridional due to stronger gradients of specific humidity in this direction. Con-

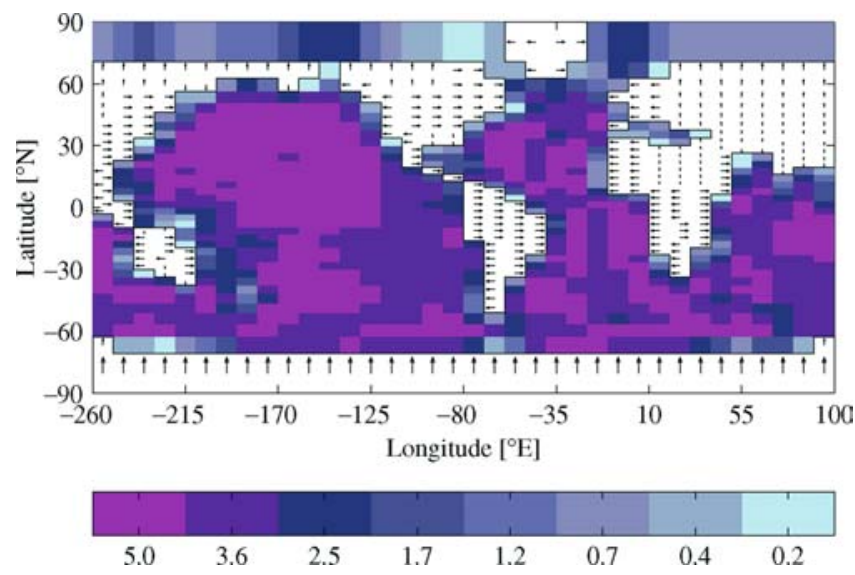

Fig. 2 Model resolution and topography (depth in $\mathrm{km}$ ). The arrows within the continental regions indicate runoff patterns 
sequently, higher values of $K_{q}$ support larger poleward moisture transports. Our nominal default value of $K_{q}$ is $10^{6} \mathrm{~m}^{2} \mathrm{~s}^{-1}$ (including some moisture advection). Edwards and Marsh (2004) investigate climate and THC states across a plausible $K_{q}$ range of $5 \times 10^{4}$ to $5 \times 10^{6} \mathrm{~m}^{2} \mathrm{~s}^{-1}$.

Figure 2 shows the model land-sea mask, indicating ocean geometry and topography, and direction of runoff for precipitation falling on each land gridbox. The resolution in this version of C-GOLDSTEIN is very coarse, $10^{\circ}$ longitude by $3^{\circ}-15^{\circ}$ latitude. Variable resolution in latitude is due to equal increments in sine(latitude), which ensure constant surface area per horizontal gridbox. The ocean comprises eight depth levels on a uniformly logarithmically stretched grid with vertical spacing increasing from $175 \mathrm{~m}$ at the surface to $1,420 \mathrm{~m}$ at depth. Only the largest-scale topographic features are well resolved, such as the East Pacific Rise and the mid-Atlantic Ridge. As indicated by the arrows in Fig. 2, land gridboxes instantaneously direct precipitation back to the ocean basins according to a runoff scheme that utilises geographical catchment areas. Despite this coarse horizontal resolution, it is significant that C-GOLDSTEIN explicitly represents longitudinal variation, which is often ignored in models of intermediate complexity.

Of particular relevance to THC stability and multiple equilibria is the representation of convective mixing. The convection scheme in C-GOLDSTEIN, introduced in an earlier study of THC stability (Edwards et al. 1998), comprises an adjustment term in the tendency equations for temperature and salinity, and ensures complete mixing in a finite number of iterations. The large model space and timescales are liable to significantly overestimate convective mixing, a problem exacerbated by the step-like topographic variations. These problems are typical of present-generation ocean climate models. Work in progress indicates that the inclusion of bottom boundary layer processes and more ad hoc convection schemes that reduce entrainment through the water column can improve water-mass properties.

Another important factor in THC stability is the northward spreading and upward mixing of Antarctic bottom water (AABW) in the Atlantic sector. In the present version of C-GOLDSTEIN, AABW formation is too weak relative to NADW formation (compared with the real world). With AABW absent from the Atlantic sector when NADW is formed (see Fig. 6b), the simulated Conveyor Belt mode of C-GOLDSTEIN is probably too stable. The formation and preservation of bottom water masses in C-GOLDSTEIN has since been improved by appending to the model a single, terrainfollowing bottom boundary layer with simplified dynamics (work in progress).

\section{Methodology}

To explore THC equilibria, we carried out ensemble experiments in $\left(\Delta F_{a}, K_{q}\right)$ parameter space, comprising
961 independent model runs of 4,000 years each. This duration of integration is usually sufficient for the THC to reach, or closely approach, equilibrium. The parameters are varied across wide ranges as follows: $\Delta F_{a}$ is varied from -0.3 to $0.3 \mathrm{~Sv}$ (i.e. from near removal to near doubling of $F_{a}$ ) in 31 steps of $0.02 \mathrm{~Sv} ; K_{q}$ is varied from $5 \times 10^{4}$ to $5 \times 10^{6} \mathrm{~m}^{2} \mathrm{~s}^{-1}$ in 31 equal logarithmic steps. While this study is motivated by intensification of the hydrological cycle under global warming, atmospheric $\mathrm{CO}_{2}$ concentration is held constant throughout the experiments in order to isolate the controlling influence of freshwater fluxes on THC equilibria.

A 4,000-year integration of C-GOLDSTEIN typically takes around $4 \mathrm{~h}$ on a single processor of a fast workstation or PC (i.e. an Intel $\mathrm{P} 3 / 1 \mathrm{GHz}$ processor with 256 MB RAM). With 961 independent model runs, this implies a net computation time of approximately 160 days for a single ensemble experiment. Clearly this makes an ensemble experiment too time consuming to run in sequence, and so a parallel approach was adopted. In particular, we used Condor (Thain et al. 2003) to execute the individual model runs of an ensemble experiment in parallel. A prototype web-based portal, developed for the GENIE project, was used to automate the process of creating and submitting experiments to Condor, as well as allow us to monitor their progress and retrieve the final results. These technologies are described in more detail in Appendix.

We start with a spinup $\left(\Delta F_{a}, K_{q}\right)$ ensemble experiment, initialising the model ocean from a uniformly cold state $\left(5^{\circ} \mathrm{C}\right.$ everywhere $)$. We then repeat the $\left(\Delta F_{a}, K_{q}\right)$ experiment nine times, this time initialising the simulations in each experiment with a different final state from the spinup experiment (i.e. of the original 961 simulations, the end states of nine of these are used as the initial conditions for nine new experiments, each of which also comprises 961 simulations). The nine final states used to initialise these runs are distributed regularly over $\left(\Delta F_{a}, K_{q}\right)$ space. Table 2 lists the $\left(\Delta F_{a}, K_{q}\right)$ parameter pairs used in the spinup experiment to obtain them. We also continue the runs in the original ensemble experiment for a further 4,000 years as a control experiment (ensemble 0), to account for any residual trends when comparing final states of the restarted

Table 2 Parameters used to spinup initial state for ensembles 1-9

\begin{tabular}{llc}
\hline $\begin{array}{l}\text { Ensemble } \\
\text { number }\end{array}$ & \multicolumn{2}{l}{$\begin{array}{l}\text { Parameter pairs used for spinning } \\
\text { up initial state }\end{array}$} \\
\cline { 2 - 3 } & $\Delta F_{a}$ & $K_{q}$ \\
\hline 1 & -0.3 & $5 \times 10^{4}$ \\
2 & -0.3 & $5 \times 10^{5}$ \\
3 & -0.3 & $5 \times 10^{6}$ \\
4 & 0.0 & $5 \times 10^{4}$ \\
5 & 0.0 & $5 \times 10^{5}$ \\
6 & 0.0 & $5 \times 10^{6}$ \\
7 & 0.3 & $5 \times 10^{4}$ \\
8 & 0.3 & $5 \times 10^{5}$ \\
9 & 0.3 & $5 \times 10^{6}$ \\
\hline
\end{tabular}


experiments to counterpart final states run for the same length of time (we find that such trends are very small).

We use the large ensembles to identify regions of parameter space that support more than one steady state of the THC. Having identified such regions, we carry out a limited series of sensitivity experiments to determine how easily the Conveyor "On" state can collapse irreversibly to the Conveyor "Off" state under a small extra source of freshwater in the North Atlantic. The strength of this extra source is based on predicted Greenland ice sheet melt rates under global warming.

\section{Results}

\subsection{Initial spinup ensemble}

The time evolution of meridional overturning (MOC) strength (not shown) reveals that, for most simulations, THC in the model approaches equilibrium after around 3,000 years. Average trends in maximum MOC strength over the fourth millennium are very small $(<0.1 \mathrm{~Sv}$ kyear $^{-1}$ ). However, a small number of simulations, mostly concentrated in the high $\Delta F_{a}$, high $K_{q}$ corner of parameter space, drift at somewhat higher rates. Detailed examination of the most extreme of these simulations reveals that they, too, are converging to a stable equilibrium, albeit on longer timescales $(\sim 10 \mathrm{ky})$. The aforementioned 4,000 year continuations of this ensemble account for these residual trends.

We now consider model forcing, THC and climate at the end of ensemble 0. Figure 3 shows fields of surface freshwater flux at nine points of the $\left(\Delta F_{a}, K_{q}\right)$ parameter space corresponding to the initial states used for the nine continued ensembles (positive values indicate net precipitation, negative values indicate net evaporation). In general, the surface freshwater flux is dominated by strong precipitation in equatorial latitudes, evaporation in the subtropics, and weaker precipitation at mid to high latitudes (this pattern resembles observations). The effect of larger $K_{q}$ is to transport more moisture to high latitudes where precipitation rates are consequently high. Under smaller $K_{q}$, little moisture is exported from the tropics/subtropics, leading to larger evaporation and precipitation rates in those regions.

To examine the equilibrium (year 4000) states obtained in each member of the ensemble, we plot key integral diagnostics in $\left(\Delta F_{a}, K_{q}\right)$ space. Starting with freshwater forcing, Fig. 4 shows net freshwater fluxes in the Atlantic, Pacific and Southern Oceans (positive values indicate net basin freshwater gain). These fluxes are strongly dependent on $\Delta F_{a}$ and $K_{q}$. The Atlantic and Pacific patterns reflect the major influence of $\Delta F_{a}$-i.e. net Atlantic freshwater flux primarily decreases with increasing $\Delta F_{a}$ (vice versa for the Pacific). However, $K_{q}$ controls a secondary opposite effect, with higher values enhancing net freshwater gain over the Atlantic and net loss over the Pacific. As the Southern Ocean lies outside the zones to which $\Delta F_{a}$ is applied, net freshwater forcing in that region is controlled by $K_{q}$ alone, with stronger freshwater gain under larger values.

As a consequence of differences in net basin freshwater flux, Atlantic-Pacific and tropical-extratropical salinity contrasts vary across parameter space (not
Fig. 3 Surface freshwater flux fields at nine points in $\left(\Delta F_{a}, K_{q}\right)$ space (fluxes in $\mathrm{m}_{\text {year }}{ }^{-1}$ ). Positive values indicate net precipitation; negative values indicate net evaporation
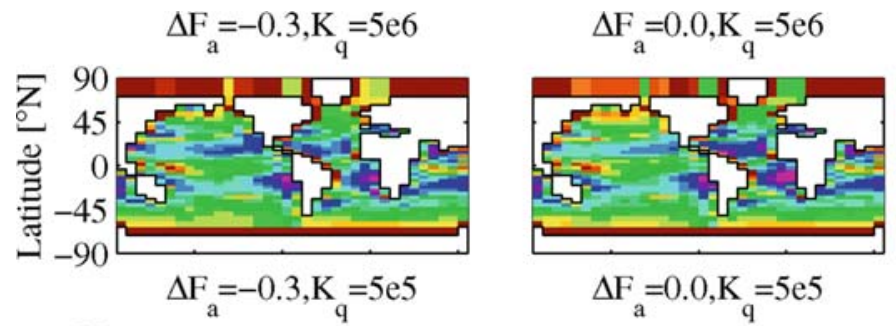

$\Delta \mathrm{F}_{\mathrm{a}}=0.0, \mathrm{~K}_{\mathrm{q}}=5 \mathrm{e} 5$
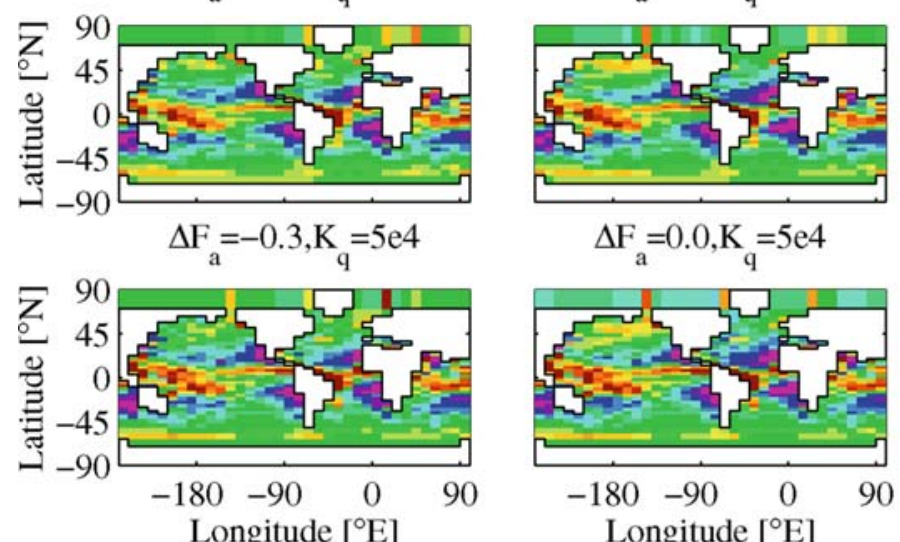

Longitude $\left[{ }^{\circ} \mathrm{E}\right]$

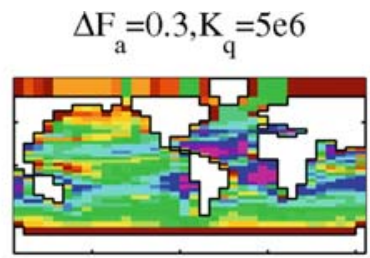

$\Delta \mathrm{F}_{\mathrm{a}}=0.3, \mathrm{~K}_{\mathrm{q}}=5 \mathrm{e} 5$

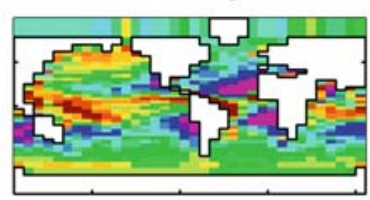

$\Delta \mathrm{F}_{\mathrm{a}}=0.3, \mathrm{~K}_{\mathrm{q}}=5 \mathrm{e} 4$

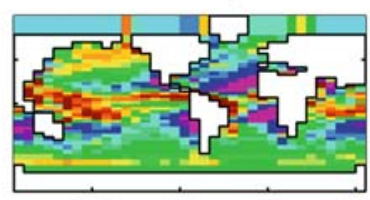

$\begin{array}{llll}-180 & -90 & 0 & 90\end{array}$

Longitude $\left[{ }^{\circ} \mathrm{E}\right]$

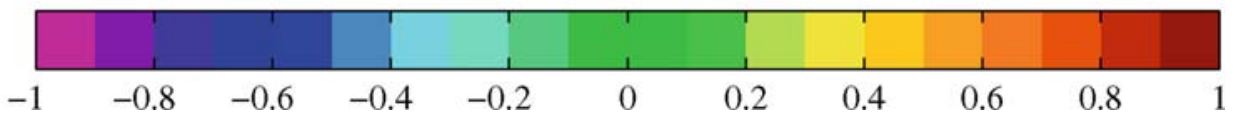



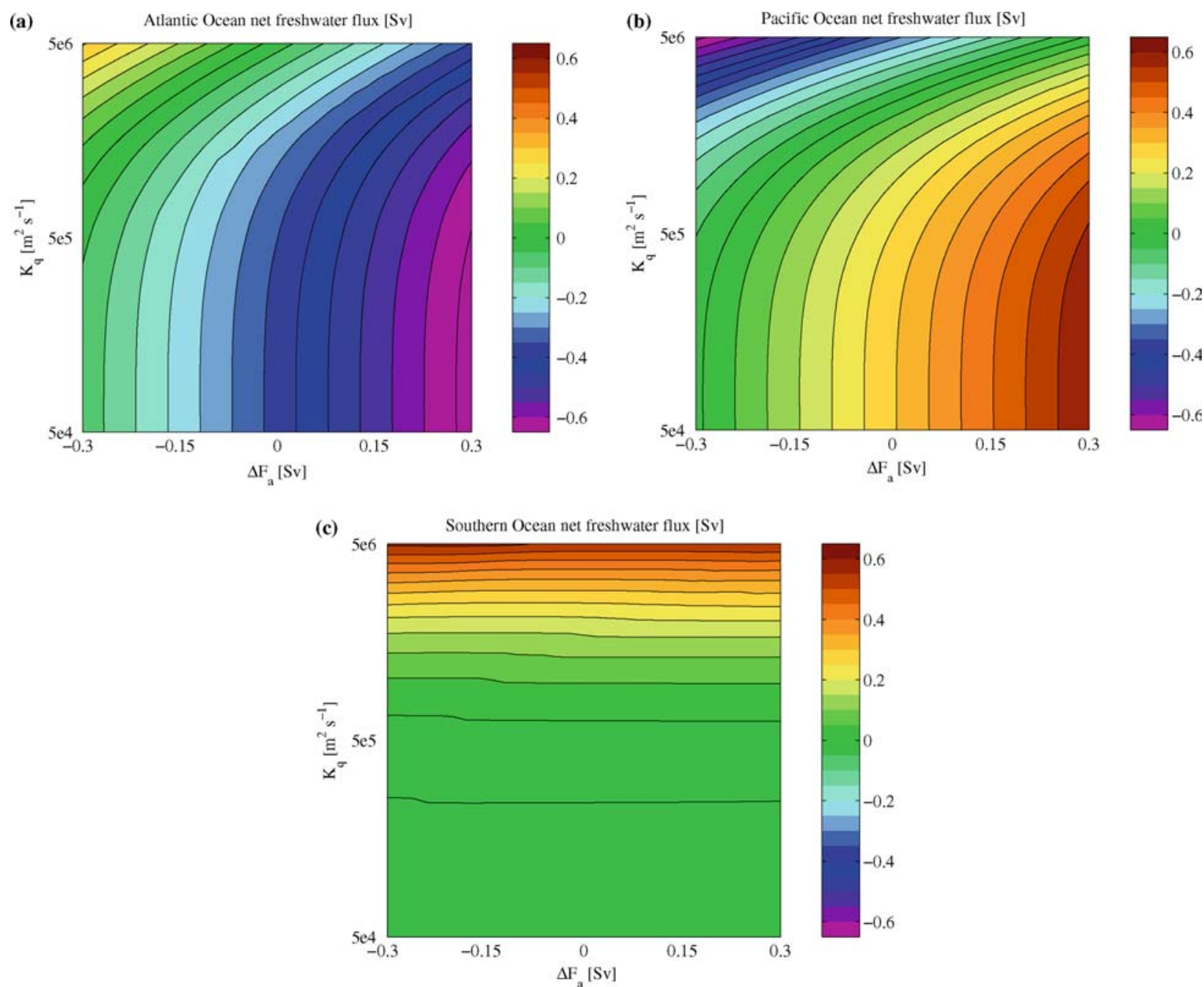

Fig. 4 Basin-net freshwater fluxes in $\left(\Delta F_{a}, K_{q}\right)$ space: a Atlantic; b Pacific; c Southern Ocean. Positive values indicate net basin freshwater gain

shown), with important implications for the nature of the THC. Particularly sensitive to the freshwater fluxes is the "Conveyor Belt" THC mode, characterised by strong northern sinking and inter-hemispheric overturning in the Atlantic sector. Two integral measures of Atlantic MOC strength in $\left(\Delta F_{a}, K_{q}\right)$ space are shown in Fig. 5a, b: basin maximum, and maximum at the southern boundary of the basin. Maxima progressively weaken southwards down the basin (hence smaller values in Fig. 5b), consistent with partial closure of overturning within the Atlantic basin. However, the good qualitative agreement between these two measures confirms that the overall maximum MOC strength is a good proxy for the strength of Conveyor Belt mode of THC in the model. In each case, two principal modes are revealed: Conveyor "On" (towards the bottom right corner) and "Off" (towards the top left corner). The Edwards and Marsh (2004) default solution at $\left(0.0,10^{6}\right)$ is within the region of the Conveyor "On" state, although close to the "cliff edge" in parameter space. Completing an integral summary of global THC, Fig. 5c, d also shows maximum (negative) overturning rates in the Pacific and Southern Oceans. Large values correspond, respectively, to: strong upwelling of deep waters throughout the Pacific; strong sinking and northward export of deep waters in the Southern Ocean. Southern sinking is dominant over the Conveyor "Off" region of parameter space, except at very high values of $K_{q}$ and very low values of $\Delta F_{a}$, for which the Pacific overturns in an Atlantic-like Conveyor "On" state (not shown).

Representative Atlantic MOC streamfunctions associated with different regions of $\left(\Delta F_{a}, K_{q}\right)$ space are shown in Fig. 6. Two principal states, with extremes in the top left and bottom right corners of Fig. 5a, correspond to the Conveyor "On" and "Off", respectively (Fig. 6a, d). Further examination of $\left(\Delta F_{a}, K_{q}\right)$ space reveals two minor regions in which additional intermediate states arise (Fig. 6b, c). A third state (Fig. 6b), characterised by shallow $(1-2 \mathrm{~km})$, weak $(\sim 8 \mathrm{~Sv})$ sinking in subtropical latitudes of the North Atlantic $\left(30-40^{\circ} \mathrm{N}\right)$ and weak inter-hemispheric exchange, is found near the top right corner of parameter space (high 

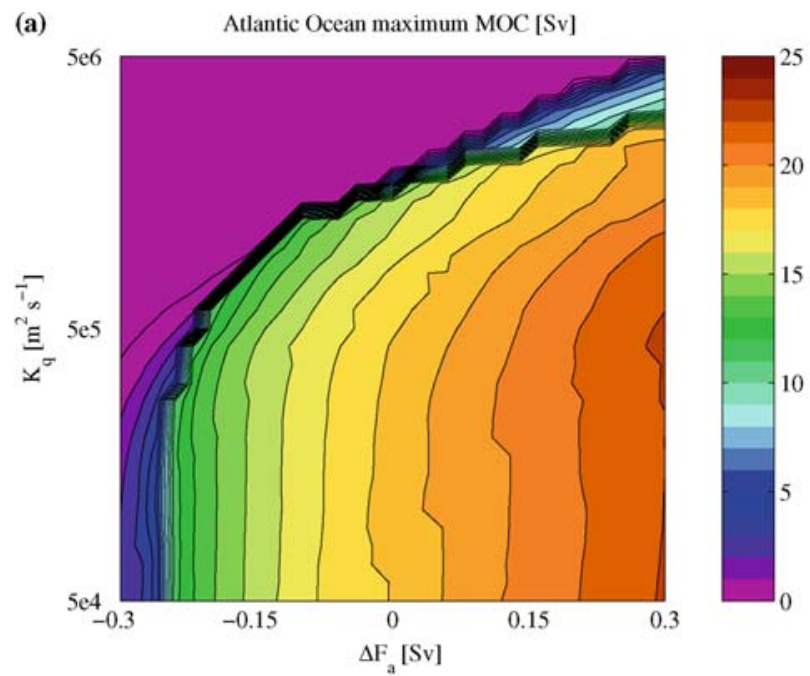

(b)
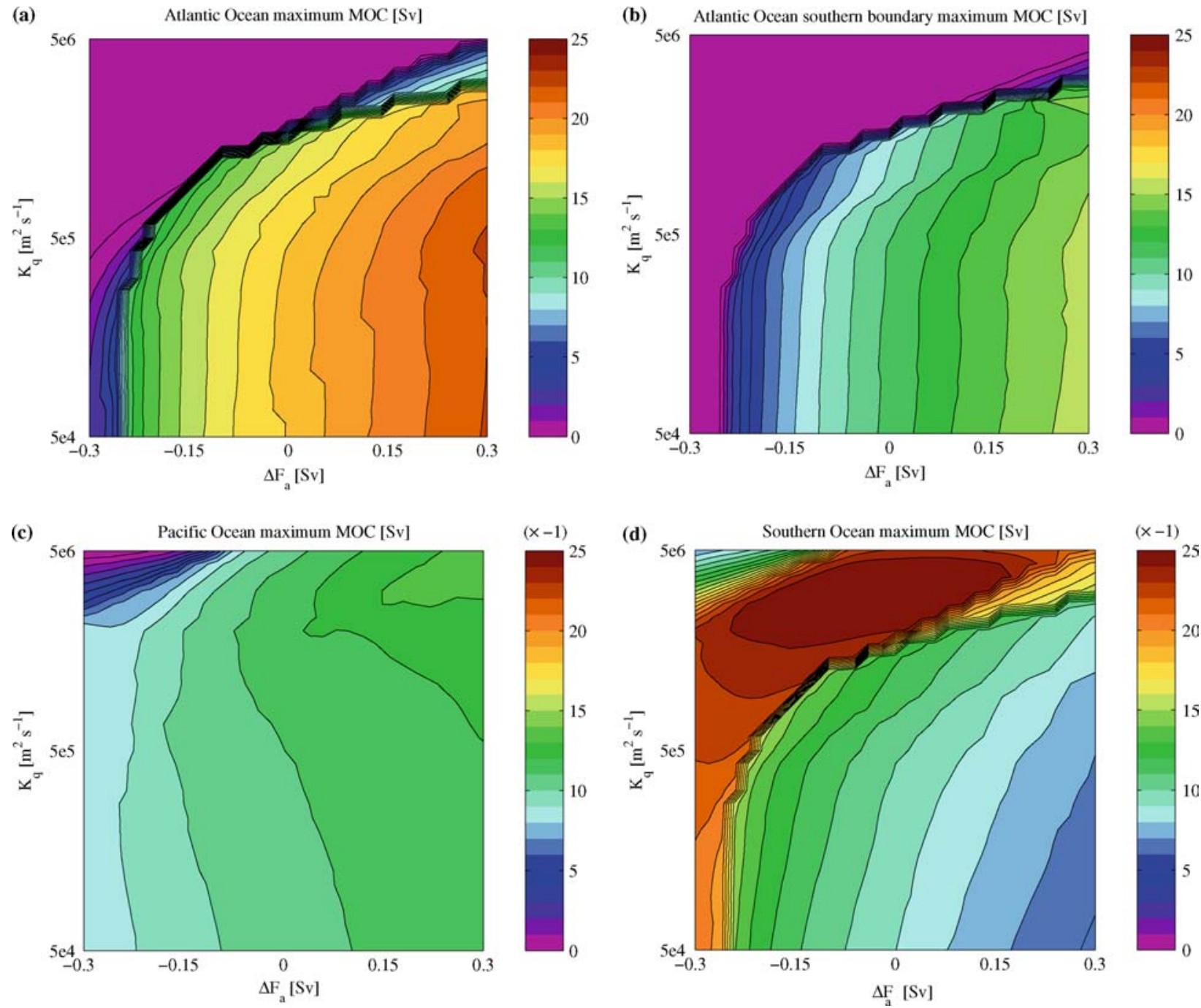

Fig. 5 Several measures of meridional overturning rate in $\left(\Delta F_{a}, K_{q}\right)$ space: a maximum everywhere within the Atlantic basin; b maximum at the southern boundary of the Atlantic basin; c minimum Pacific overturning (multiplied by -1 ); d minimum Southern Ocean overturning (multiplied by -1 )

$\Delta F_{a}$, high $K_{q}$ ). A fourth state (Fig. 6c), characterised by shallow $(0.5-1.5 \mathrm{~km})$ and very weak $(\sim 6 \mathrm{~Sv})$ sinking at subpolar latitudes and a weak ( $\sim 4 \mathrm{~Sv})$ abyssal cell of opposite sign, is found near the bottom left corner of parameter space (low $\Delta F_{a}$, low $K_{q}$ ). In this case, Atlantic overturning is confined to the northern hemisphere, with a degree of equatorial symmetry. Both of these states persist across small regions of $\left(\Delta F_{a}, K_{q}\right)$ space, in the transition zone between the dominant Conveyor "On" and "Off" states. Note that, by using more elaborate methods to vary the initial conditions, more steady states can be found (up to 12 for fixed parameter combinations; JD Annan and JC Hargreaves, personal communication, 30/01/03). However, the additional states appear to be characterised by very slightly different convection patterns and not by significantly different circulation states.

The consequences of changes in $K_{q}$ and $\Delta F_{a}$, for regional climate, are shown in Fig. 7. North Atlantic regional-mean air temperature (Fig. 7a) generally increases with $K_{q}$ through atmospheric warming by latent heat transport under more humid conditions. Increasing relative humidity also acts to warm the atmosphere through reduced planetary long-wave radiation, although this effect is minor compared with the stronger latent heat release. The THC influence on Atlantic climate is revealed by differences of up to $2^{\circ} \mathrm{C}$ between neighbouring locations in $\left(\Delta F_{a}, K_{q}\right)$ space, coincident with "On" and "Off" states of the Conveyor Belt. A similar pattern of variation appears in total sea ice volume (Fig. 7b; no sea ice occurs in the Southern Ocean, so this diagnostic represents Arctic sea ice). Disappearance of all sea ice at high values of $K_{q}$ is consistent with strong latent heat release (accompanying strong precipitation) at high latitudes. Maximum sea ice volume at low $K_{q}$ and low $\Delta F_{a}$ is consistent with colder polar climate under collapsed Atlantic overturning. 
Fig. 6 Representative members of the four principal states, at the $\left(\Delta F_{a}, K_{q}\right)$ values indicated: a Conveyor "Off"; b weak, interhemispheric overturning; c weak, northern-confined overturning; d Conveyor "On". The states are positioned to reflect their typical location in $\left(\Delta F_{a}, K_{q}\right)$ space
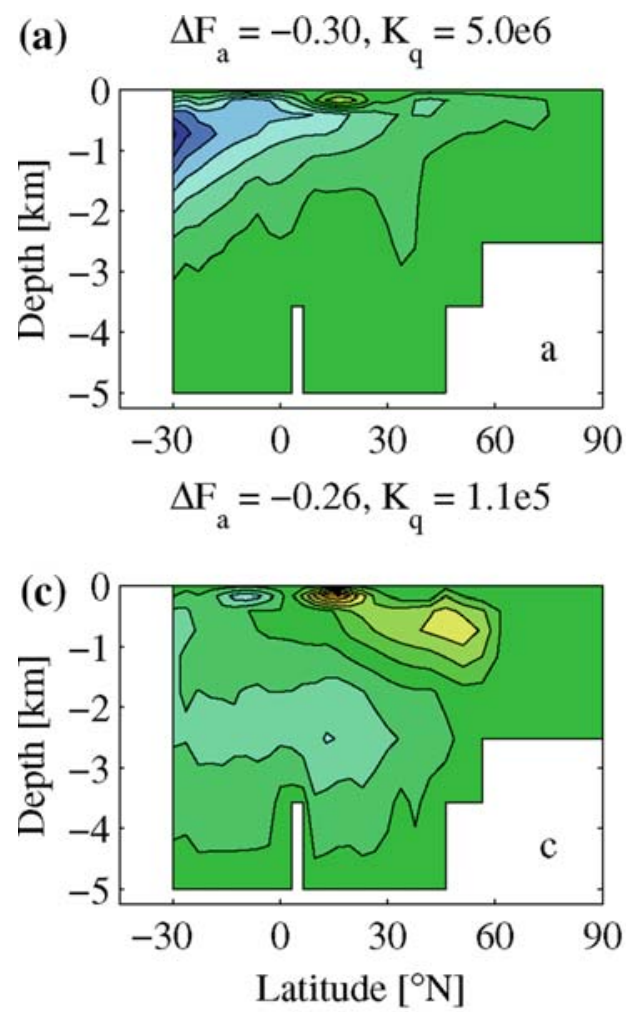
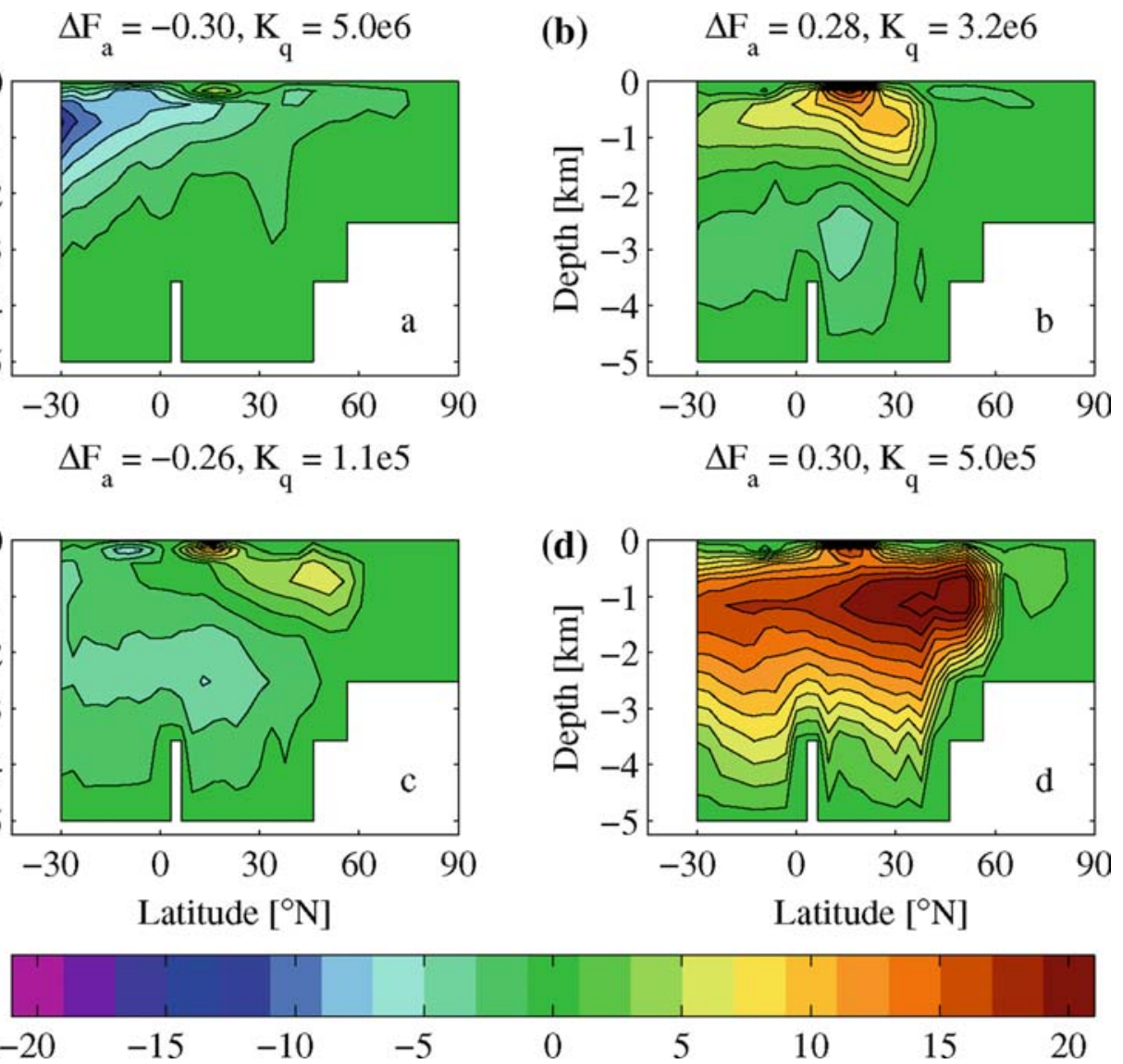
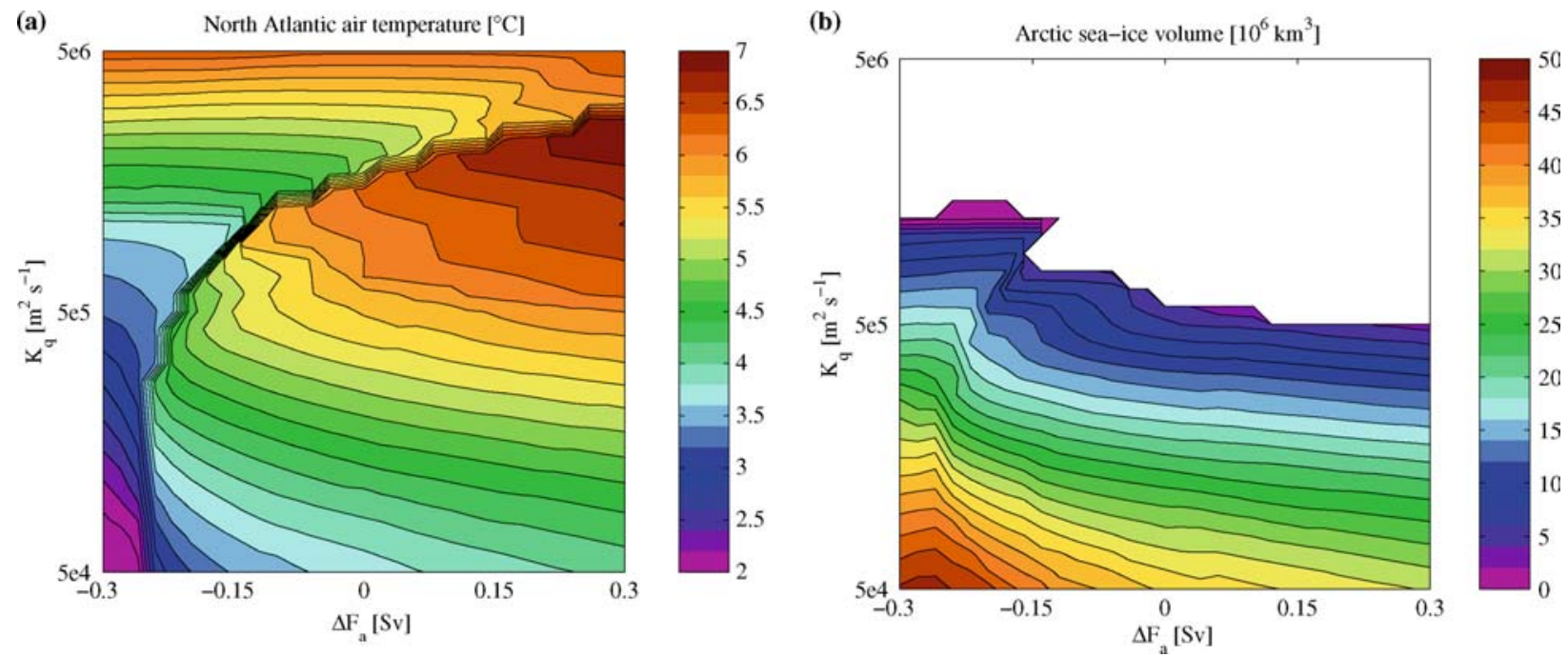

Fig. 7 Further integral diagnostics in $\left(\Delta F_{a}, K_{q}\right)$ space: a mean North Atlantic air temperature (averaged over $70^{\circ} \mathrm{W}$ to $\left.10^{\circ} \mathrm{E}, 40-90^{\circ} \mathrm{N}\right)$; $\mathbf{b}$ Arctic sea ice volume. Present-day observed values are estimated to be $3.7^{\circ} \mathrm{C}$ and $25 \times 10^{6} \mathrm{~km}^{3}$

4.2 The nine continued ensembles: identifying regions of multiple equilibria in $\left(\Delta F_{a}, K_{q}\right)$ parameter space

Differences between maximum Atlantic Conveyor strength at the end of each continued ensemble (1-9) and that at the end of ensemble 0 (not shown) exceed $\pm 2 \mathrm{~Sv}$ in a limited range of 2-parameter space, more-or-less following the threshold between Conveyor "On" and "Off". The tendency is for the THC to remain in a Conveyor "Off" state in ensembles restarted from that state, and vice versa for ensembles restarted from the Conveyor "On" state. These differences between 

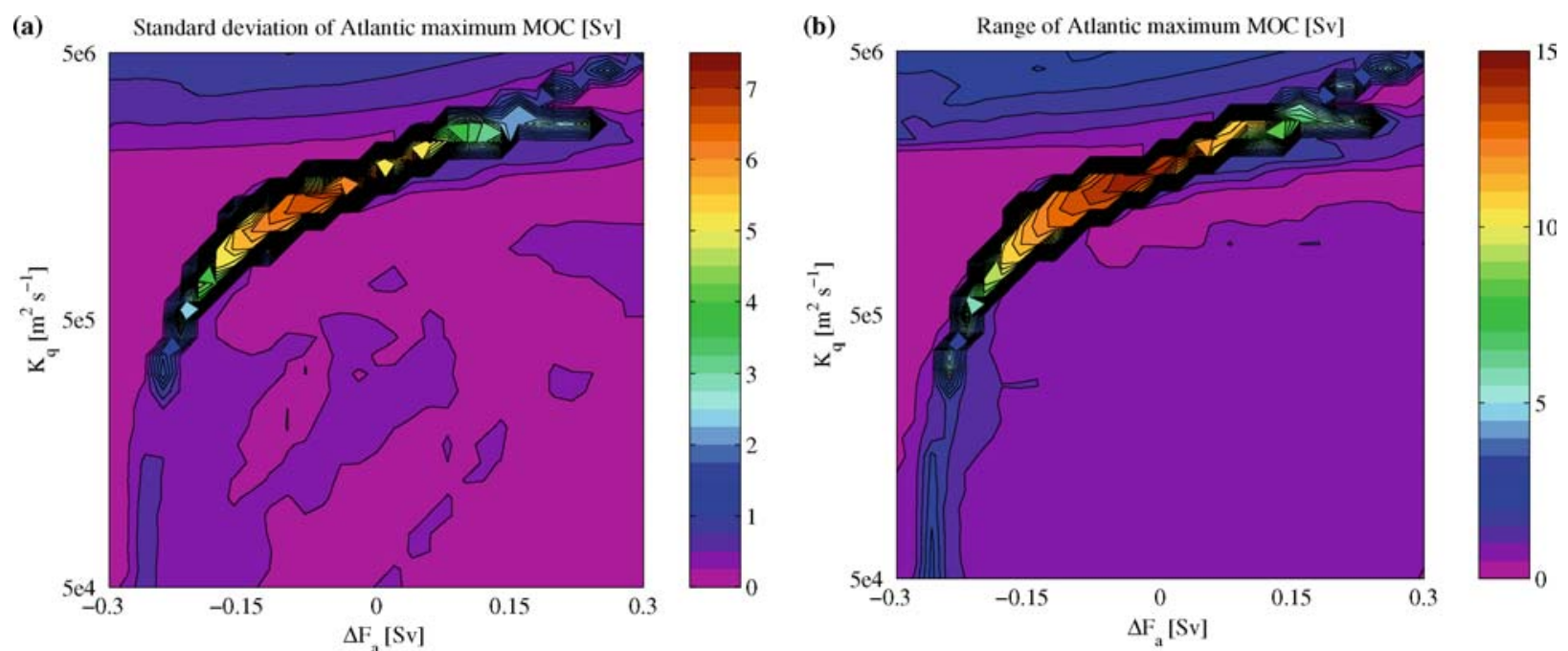

Fig. 8 a Standard deviation, b range, of maximum Atlantic MOC strength, based on ensembles 1-9

ensembles 1-9 and ensemble 0 indicate the existence of multiple equilibria, classically defined as alternative steady states arising under the same parameter settings, which may be excited through differences in the initial state. To identify more clearly the broadest extent of multiple equilibria, Fig. 8 shows the standard deviation and range of maximum Atlantic MOC strength, based on the nine continued equilibrium solutions at each $\left(\Delta F_{a}, K_{q}\right)$ point. Even on this basis, the region where multiple equilibria occur is rather limited in $\left(\Delta F_{a}, K_{q}\right)$ space, although the $\log$ axis used for $K_{q}$ distorts the extent in that dimension.

Having identified where multiple equilibria arise in the parameter space, in Fig. 9 we plot the Atlantic Conveyor strength for ensembles 0 (red) and ensem- bles 1-9 (black), as a function of $\Delta F_{a}$, at nine progressively higher values of $K_{q}$ in the range $6.8 \times 10^{5} \leq K_{q} \leq 2.3 \times 10^{6}$. This $K_{q}$-range incorporates the biggest differences observed in Fig. 8. It is clear from Fig. 9 that there exists a set of $\left(\Delta F_{a}, K_{q}\right)$ parameter pairs for which two quite different THC states are stable: Conveyor "On" and "Off" states. For these parameter pairs, the THC is bistable. For all other parameter pairs (left and right of the bistable range of $\Delta F_{a}$ in Fig. 9), only one stable state of the THC is observed-i.e. the THC is monostable. Only at the highest values of $K_{q}$ are more than two steady states evident (the "intermediate" states in these cases are variants of the weak inter-hemispheric overturning state illustrated in Fig. 6b).
Fig. 9 Atlantic Conveyor strength for ensembles 0 (red) and ensembles 1-9 (black) as a function of $\Delta F_{a}$, at nine progressively higher values of $K_{q}$ in the range $6.8 \times 10^{5} \leq$ $K_{q} \leq 2.3 \times 10^{6}$. The arrows in the top left and centre panels indicate regions of parameter space at which extreme ranges of MOC strength occur (see Fig. 12 and associated text)
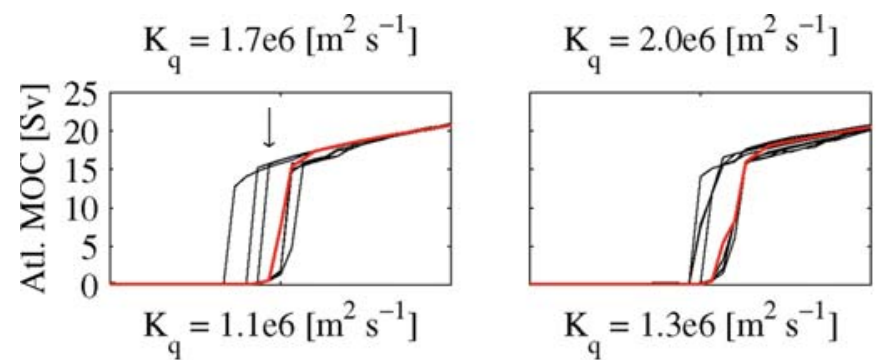

$$
\mathrm{K}_{\mathrm{q}}=2.3 \mathrm{e} 6\left[\mathrm{~m}^{2} \mathrm{~s}^{-1}\right]
$$
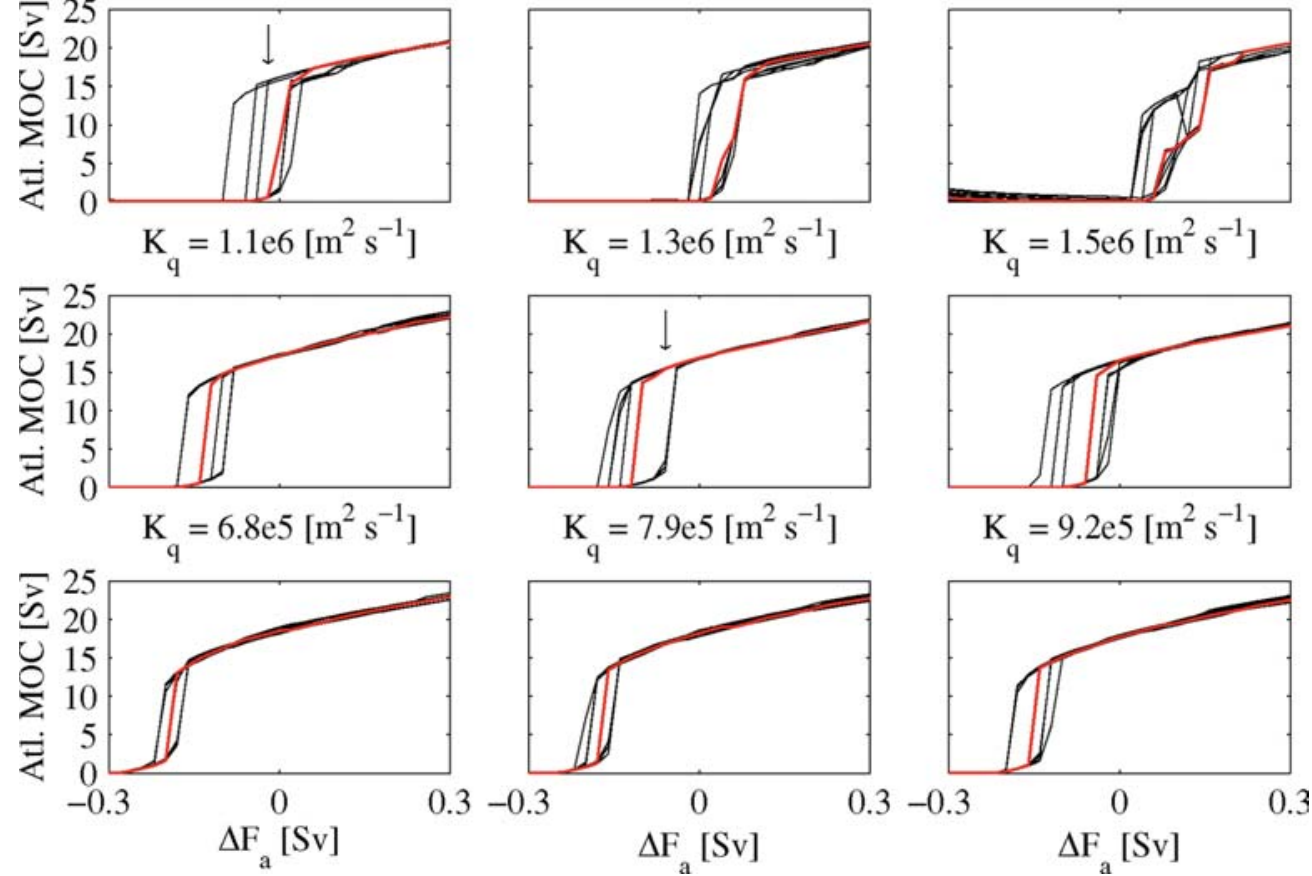
Fig. 10 Extreme pairs of Conveyor "On" and "Off" Atlantic MOC streamfunctions for: a Conveyor On at end of spinup, Off at end of continuation, at $\Delta F_{a}=-0.06$, $K_{q}=1.3 \times 10^{6} ; \mathbf{b}$ Conveyor Off at end of spinup, On at end of continuation, at $\Delta F_{a}=-0.02$, $K_{q}=1.7 \times 10^{6}$ (in $\mathrm{Sv}$ )

$$
\begin{gathered}
\Delta \mathrm{F}_{\mathrm{a}}=-0.06, \mathrm{~K}_{\mathrm{q}}=1.3 \mathrm{e} 6 \\
\text { Ensemble } 0
\end{gathered}
$$

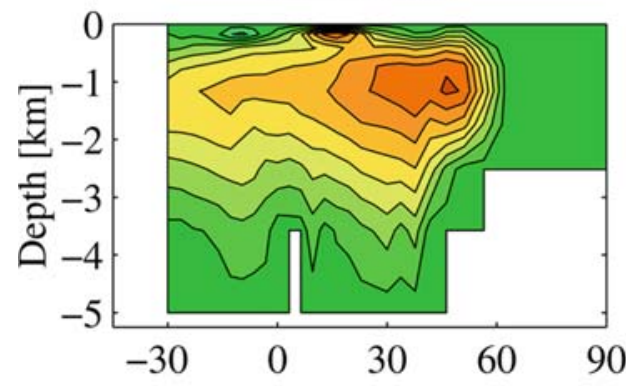

Ensemble 3

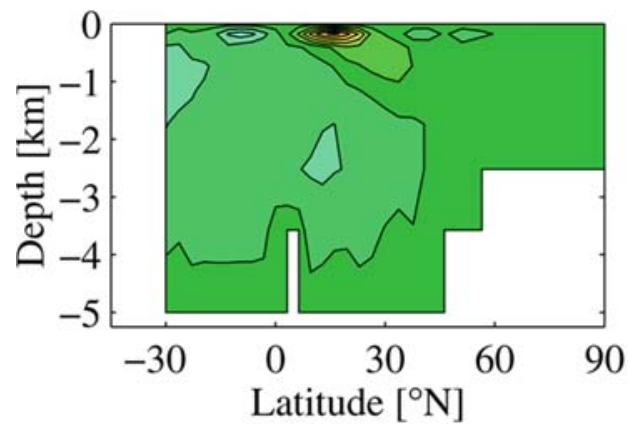

$$
\Delta \mathrm{F}_{\mathrm{a}}=-0.02, \mathrm{~K}_{\mathrm{q}}=1.7 \mathrm{e} 6
$$

Ensemble 0

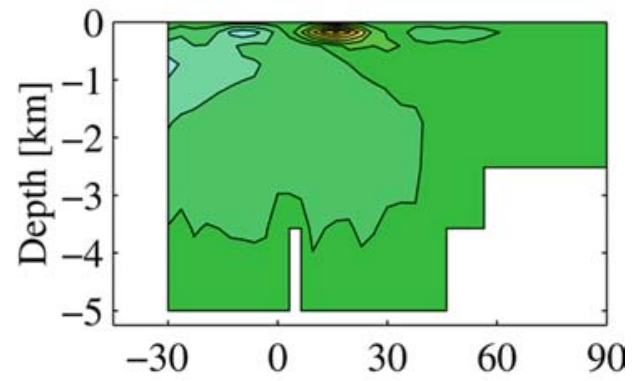

Ensemble 8

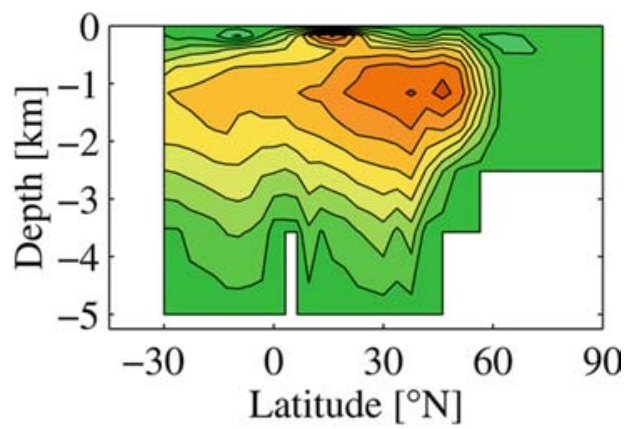

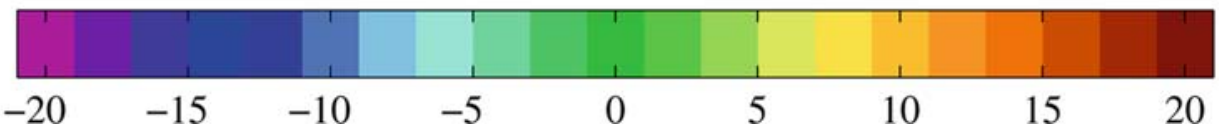

Figure 10 shows extreme pairs of Conveyor "On" and "Off" Atlantic MOC streamfunctions for: Conveyor "Off" at end of spinup, "On" at end of continuation (Fig. 10a); Conveyor "On" at end of spinup, "Off" at end of continuation (Fig. 10b). These states are indicated by arrows in Fig. 9. Figure 11 shows a map of airtemperature difference corresponding to the above THC pairs. The effect of maintaining the Conveyor "Off" state is a colder North Atlantic and warmer South Atlantic - the classic "bipolar seesaw" effect (Broecker 1998; Stocker 1998). Conversely, maintaining the Conveyor in the "On" state yields a reversed seesaw pattern. The bipolar seesaw obtained here is relatively weak, with North-South amplitude of $\sim 3^{\circ} \mathrm{C}$. This may be due to factors such as: neglected seasonality (since cooling at northern mid-latitudes, under a collapsed Conveyor, would be enhanced during winter); low spatial resolution; and the use of a simplified atmosphere. This weak seesaw response may have implications for THC stability. Lower air temperature over the sinking region will promote surface cooling through sensible and latent heat fluxes. This will tend to stabilise a collapsing THC, through increased surface density in the sinking region. The limited cooling that we find may explain a degree of the THC bistability identified here. We return to this issue in the Discussion.

To more generally characterise multiple equilibria, we reinterpret THC strength in 2-parameter space as a function of just one quantity, namely the net freshwater input to the Atlantic (as plotted in Fig. 4a). Figure 12 shows Atlantic Conveyor strength as a function of this net freshwater flux, for the final states of ensembles 1-9. Lines connect simulations with $\left(\Delta F_{a}, K_{q}\right)$ parameters in common, but for which maximum overturning rates differ by at least $5 \mathrm{~Sv}$. That these connections are nearvertical suggests that net freshwater flux is almost entirely controlled by $\Delta F_{a}$ and $K_{q}$, rather than the THC. If the THC itself played an important role in controlling the net freshwater flux, these connecting lines would be more diagonal in aspect. That the net freshwater flux is strongly controlled by $\Delta F_{a}$ and $K_{q}$, rather than the THC, is also suggested by the mismatch between smooth variation of this flux and highly non-linear variation of Atlantic overturning strength, across $\left(\Delta F_{a}, K_{q}\right)$ space (comparing Figs. 4a, 5a). Note that the limited area of multiple steady states in $\left(\Delta F_{a}, K_{q}\right)$ space translates into a broader range of -0.30 to $-0.05 \mathrm{~Sv}$ net freshwater flux.

In Fig. 12, both Conveyor "On" and "Off" states of the THC exist under the same net freshwater flux, but under two distinct sets of conditions: (1) for the same $\left(\Delta F_{a}, K_{q}\right)$ combination but different initial states (indicated in Fig. 12 by long vertical lines connecting low and high values of THC strength obtained in experiments sharing the same parameters); (2) for different $\left(\Delta F_{a}, K_{q}\right)$ combinations. Case (1) is simply another view of the multiple equilibria identified in Figs. 8, 9 and 10. Case 

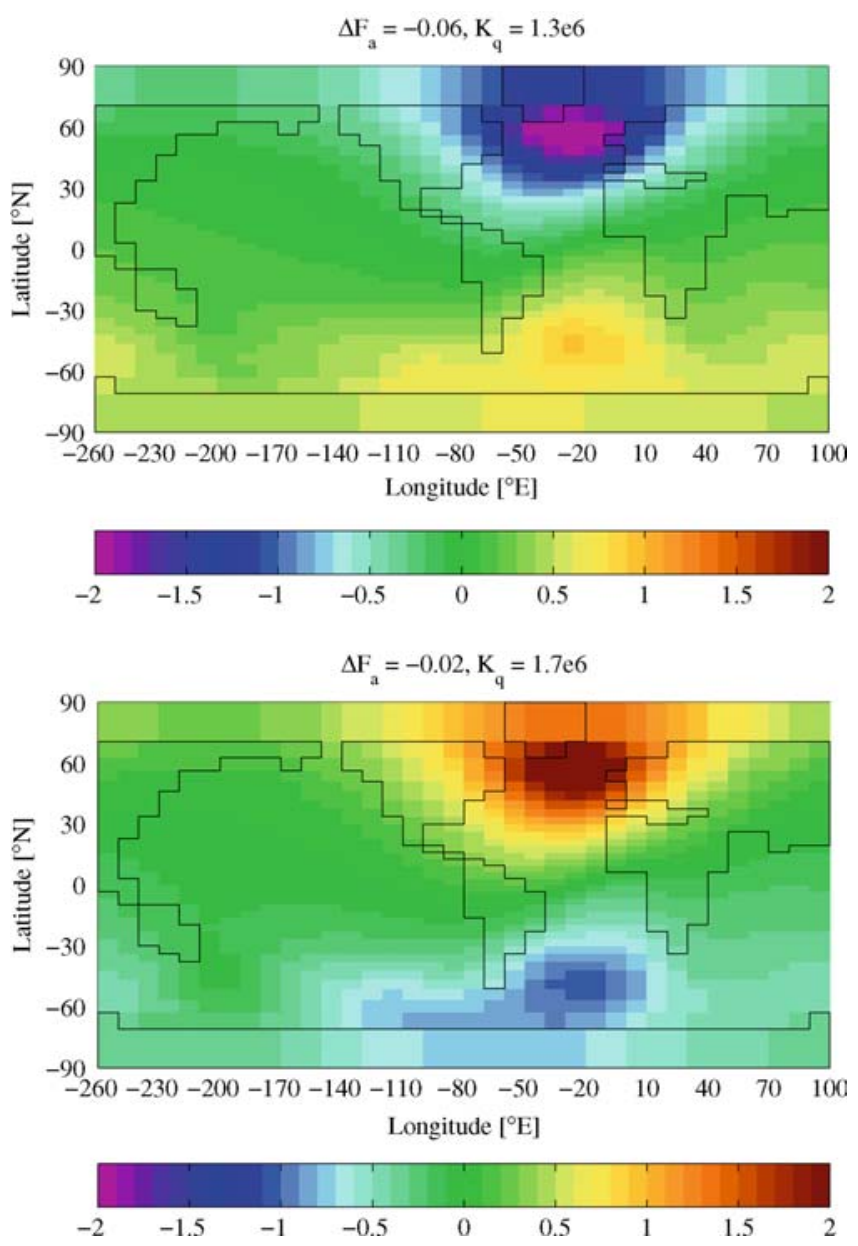

Fig. 11 Air temperature difference (lower panel state subtract upper panel state) corresponding to the change in MOC state shown in Fig. $12 \mathrm{a}, \mathrm{b}\left(\right.$ in $\left.{ }^{\circ} \mathrm{C}\right)$

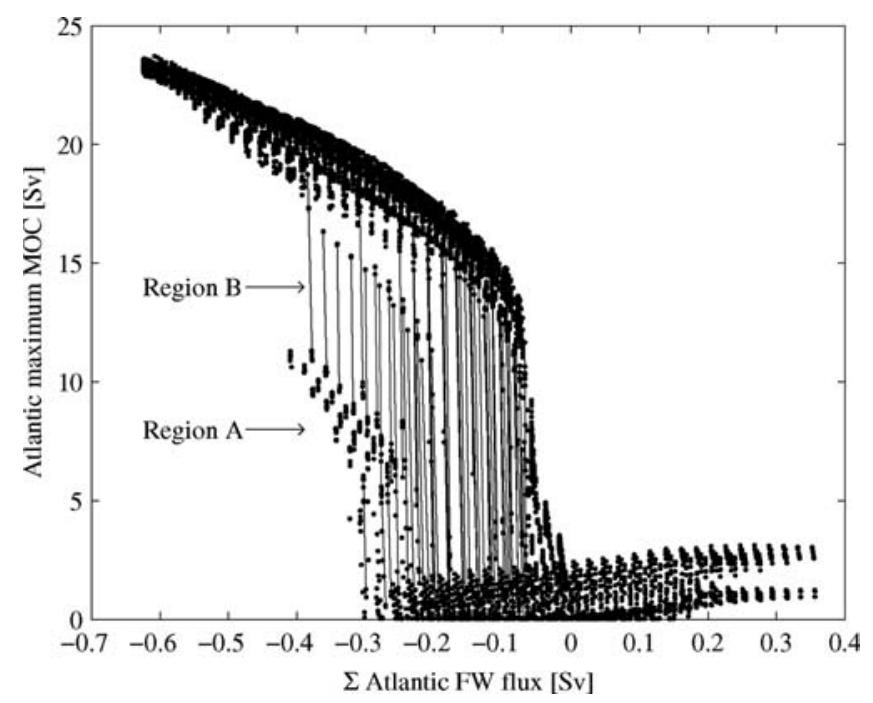

Fig. 12 Atlantic Conveyor strength as a function of net freshwater flux over whole Atlantic, for the nine ensembles. Lines connect experiment pairs (same $\Delta F_{a}, K_{q}$; different initial state) for which differences exceed $5 \mathrm{~Sv}$. Intermediate strength regions A and B are discussed in the text
(2) arises due to a combination of subtle factors. Firstly, the two THC states can be associated with different spatial patterns of freshwater flux. For example, compare the Atlantic freshwater flux fields in the bottom centre and top right panels of Fig. 3. These patterns yield almost identical basin-net fluxes (Fig. 4a) but support Conveyor "On" and "Off" states respectively (Fig. 5a). Larger values of $K_{q}$ lead to a stronger contrast between low-latitude evaporation and high-latitude precipitation, with the resulting freshwater gain over northern sinking sites prohibiting overturning. Smaller values of $K_{q}$ (which, combined with different values of $\Delta F_{a}$, result in the same basin-net freshwater flux) lead to weaker local freshwater fluxes, which permit the Conveyor "On" state. Secondly, $K_{q}$ impacts on thermal forcing of the THC through varying degrees of latent heat release at high latitudes: at large values of $K_{q}$, up to $30 \mathrm{~W} \mathrm{~m} \mathrm{~m}^{-2}$, more latent heat is released poleward of $50^{\circ} \mathrm{N}$ in the Atlantic sector. In other words, similar net freshwater fluxes are shared by quite different climate (and THC) states.

Aside from Conveyor "On" and "Off" states, we note the existence of two distinct regions, $\mathrm{A}$ and $\mathrm{B}$, of intermediate strength states in Fig. 12. Both of these regions correspond to variants of the weak inter-hemispheric overturning state identified earlier (Fig. 6b). In region A, sinking in the North Atlantic occurs in subtropical latitudes $\left(30^{\circ} \mathrm{N}\right)$ and is considerably shallower and weaker than the Conveyor "On" state. In region B, overturning is somewhat stronger, with deeper sinking $(2-2.5 \mathrm{~km})$ at more northerly latitudes $\left(40-50^{\circ} \mathrm{N}\right)$.

\subsection{THC sensitivity to freshwater flux perturbations}

Based on the findings of ensembles $0-9$, we now explore the response of the THC to small freshwater flux anomalies, with initial conditions taken from solutions obtained in and around the region of $\left(\Delta F_{a}, K_{q}\right)$ parameter space where multiple equilibria exist. Experiments designed to explore the THC response to deglacial freshwater flux anomalies typically apply $0.1 \mathrm{~Sv}$ for 500 years to represent melting of the Laurentide ice sheet (e.g. Manabe and Stouffer 1997). Melting of the Greenland ice sheet under long-term (multi-centennial) global warming may release a similar meltwater pulse. For example, by forcing a fully dynamic thermomechanical ice sheet model with climatic warming under $\mathrm{CO}_{2}$ rise, with emphasis on global sea level rise, $\mathrm{Hu}-$ ybrechts and DeWolde (1999) find that melting of the Greenland ice sheet can contribute up to $60 \mathrm{~cm}$ century $^{-1}$. This corresponds to a sustained freshwater pulse of $\sim 0.07 \mathrm{~Sv}$.

Based on these estimates of past and future meltwater pulses, we specify an extra freshwater flux of $0.1 \mathrm{~Sv}$, equally distributed as a source term in the surface freshwater flux for ocean gridboxes in the Atlantic zone $50-70^{\circ} \mathrm{N}$, over periods in the range $10-1,000$ years. The consequent volumetric freshwater gain therefore varies in the range $1-100 \mathrm{~Sv}$ years. The freshwater flux 


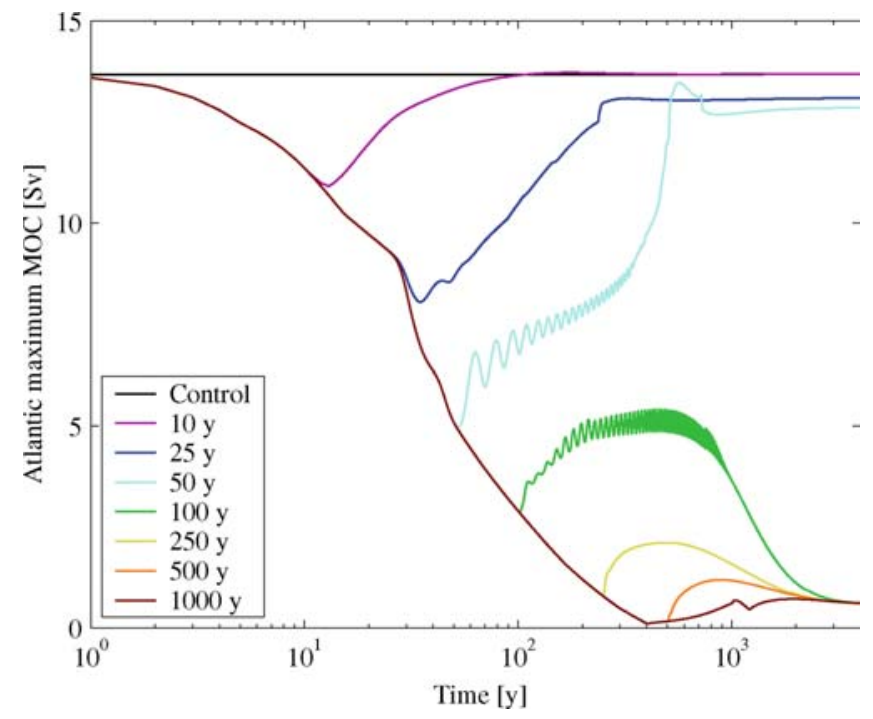

Fig. 13 Time series of Atlantic Conveyor strength over 4,000 years for a control simulation plus seven experiments. Each experiment is initially forced by progressively durable anomalous freshwater flux of $0.1 \mathrm{~Sv}$ over $50-70^{\circ} \mathrm{N}$ in the Atlantic. All experiments are started from the same initial state (ensemble 0 , parameter pair $\Delta F_{a}=-0.10$, $K_{q}=1.3 \times 10^{6}$ ). For clarity a $\log _{10}($ time $)$ axis has been used

anomaly applied here is idealized as a constant source term.

In the first instance, we apply the extra freshwater flux during the first 10-1,000 years in 4,000-year continuations of a selected ensemble 0 integration, to investigate the sensitivity of model THC to irreversible collapse under such forcing. The ensemble 0 integration selected is from a $\left(\Delta F_{a}, K_{q}\right)$ combination under which the "Conveyor On" THC is in a vulnerable state. As an example we choose the parameter pair $\left(\Delta F_{a}=-0.10\right.$, $K_{q}=1.3 \times 10^{6}$ ), for which the THC is bistable, as indicated by an arrow in the centre panel of Fig. 9. Figure 13 shows the time series of Atlantic Conveyor strength for a control experiment and seven freshwater perturbation experiments, which are forced by progressively longer meltwater pulses. For those experiments in which the THC recovers, we note the re-equilibration is to stable states with slightly weaker overturning than in control experiment.

During integrations with freshwater forcing close to the threshold duration, damped oscillations are evident. These are typically about $1 \mathrm{~Sv}$ in amplitude (in terms of maximum overturning) and have a period of approximately 15 years. The oscillations can be particularly persistent (for several thousand years) in simulations where the pulse duration is very close to that at which the THC "bifurcates" between irreversible collapse and recovery (from additional simulations in the case above, this was found to be between 87 and 88 years). Close examination of the Atlantic streamfunction during the oscillatory period reveals that the oscillations are small perturbations on a particular MOC state rather than oscillations between different MOC states. In the case of the simulations shown, the MOC state during the oscillatory period most closely resembles that of the weak northern-confined overturning state (Fig. 6c). The oscillations consist of out of phase cycles of growth and decline in shallow and deep overturning cells. Above the region of strongest MOC oscillation we find that the fluxes of heat and freshwater are out of phase and possibly act to drive the oscillatory behaviour.

Complete collapse of the THC in Fig. 13 is due to a reduction of surface density in the northern sinking region through changes in both heat and freshwater fluxes. In order to isolate the role of these two fluxes, we repeated the experiments with heat fluxes or freshwater fluxes (apart from the imposed anomaly) held constant everywhere at initial values (i.e. the heat or freshwater flux could not evolve dynamically and behaved as if no freshwater pulse was applied). Heat fluxes are fixed globally, while freshwater fluxes are fixed in the Atlantic either North or South of $30^{\circ} \mathrm{N}$, to investigate whether local or remote effects on the hydrological cycle act to promote THC collapse. Figure 14 shows the corresponding time series for two sets of fixed flux experiments. Under fixed heat flux (Fig. 14a), the overturning weakens to around $10 \mathrm{~Sv}$ in all cases, thereafter stabil-
Fig. 14 As Fig. 13, except: a ocean-atmosphere heat fluxes held constant everywhere (to the values at the end of the spinup used to initialise these runs); b ocean-atmosphere freshwater fluxes held constant in the Atlantic northward of $30^{\circ} \mathrm{N}$
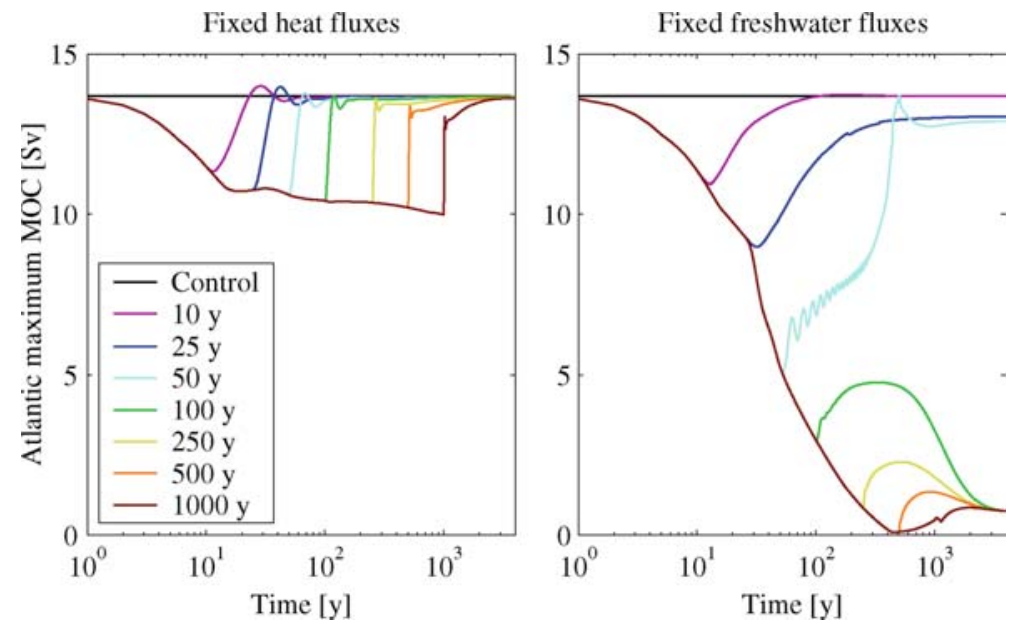
ising until the meltwater pulse ends, when the MOC abruptly recovers to the initial strength. While the initial impact of freshwater forcing is to stratify the surface ocean and weaken the THC, it is the consequent reduction of heat loss to the atmosphere that further weakens, and ultimately collapses, the THC. This heat loss is associated with strong convection in the initial state. Under fixed freshwater fluxes South of $30^{\circ} \mathrm{N}$ (not shown) there is no discernible difference compared to the full-coupled experiments. Under fixed freshwater fluxes North of $30^{\circ} \mathrm{N}$ (Fig. 14b), the only difference is an absence of small-amplitude oscillations in the case of 100year freshwater forcing. This suggests that these oscillations arise through weak coupling of the THC and the hydrological cycle in mid-latitudes. The fixed flux experiments otherwise confirm that reduced surface heat loss is the key factor in MOC collapse.

Having established that the THC is vulnerable to irreversible collapse under $0.1 \mathrm{~Sv}$ sustained for a sufficient duration, we apply $0.1 \mathrm{~Sv}$ for intermediate period of 250 years in a series of ensemble 0 continuations, using initial states that are progressively closer to the monostable regime. In a series of six initial states, $K_{q}=1.3 \times 10^{6}$, while $\Delta F_{a}$ varies in the range -0.10 to 0.00 . Figure 15 shows the corresponding time series of MOC strength. As the initial state shifts closer to the monostable regime, THC reduction becomes less pronounced, and irreversible collapse is only obtained in the original case and its nearest neighbour along the $\Delta F_{a}$ axis.

Finally, we apply the same freshwater forcing $(0.1 \mathrm{~Sv}$ for 250 years) to a range of "most vulnerable" initial states, varying both $K_{q}$ and $\Delta F_{a}$. These states correspond to the ensemble 0 "Conveyor On" solutions closest to the "Off" state in Fig. 9. Figure 16 shows the corresponding times series of MOC strength. Similar to the

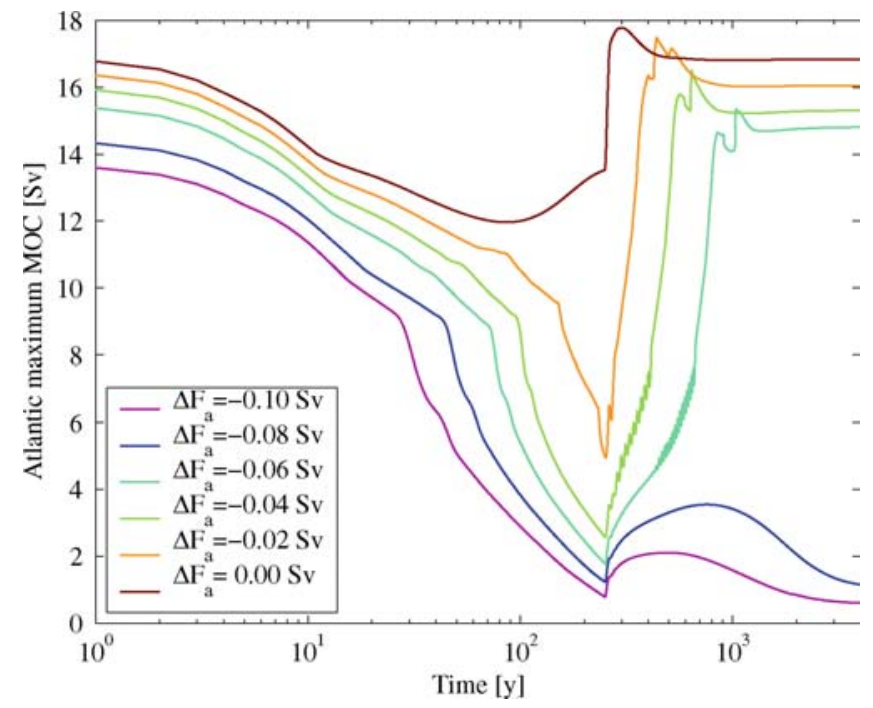

Fig. 15 Time series of Atlantic Conveyor strength under anomalous freshwater flux of $0.1 \mathrm{~Sv}$ over $50-70^{\circ} \mathrm{N}$ in the Atlantic applied for 250 years. Experiments start from a series of initial states (ensemble $0, K_{q}=1.3 \times 10^{6}, \Delta F_{a}$ in the range -0.10 to 0.00 ). For clarity a $\log _{10}$ (time) axis has been used

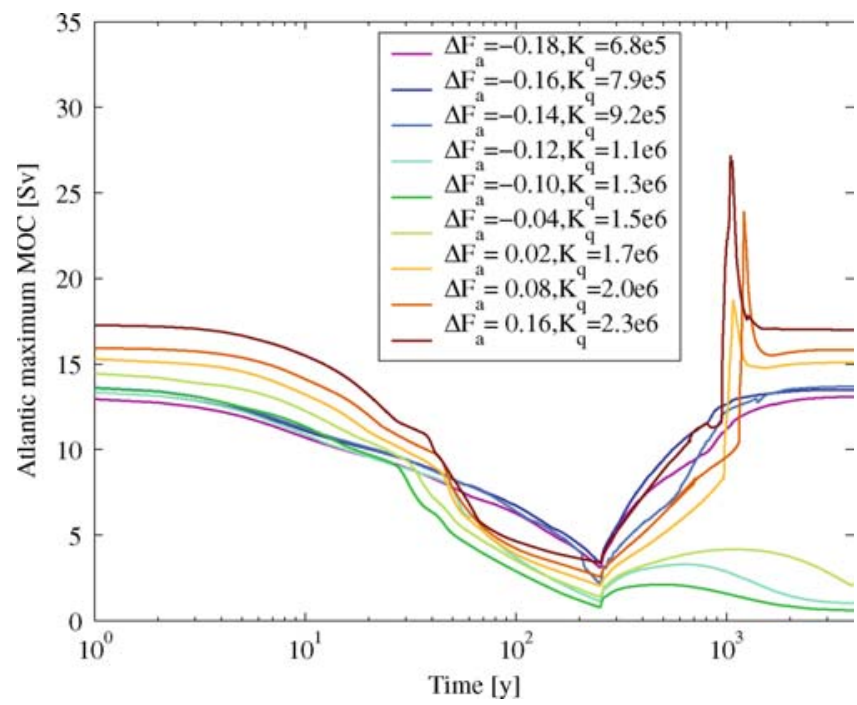

Fig. 16 As Fig. 15, continuing from a series of "most vulnerable" initial states - see text for details. For clarity a $\log _{10}$ (time) axis has been used

results shown in Fig. 15, the THC in these simulations mostly recovers, although it remains irreversibly collapsed in a third of the cases examined. These latter cases include that used in Fig. 13, and those either side of it in $\left(\Delta F_{a}, K_{q}\right)$ space. We note occasional "overshooting" of MOC strength on recovery, by up to $10 \mathrm{~Sv}$ on centennial timescales, in three cases of high $\Delta F_{a}$ and high $K_{q}$. This behaviour is consistent with the reorganisation of the THC on different timescales in the northern and southern hemispheres.

\section{Discussion}

Using an efficient climate model, and novel computing methods, we have mapped Atlantic overturning strength across 2-parameter space. The parameters used represent two key factors determining surface freshwater flux over the ocean, namely the intensity of the global hydrological cycle (controlled by atmospheric moisture diffusivity, $K_{q}$ ) and the net atmospheric transport of moisture from the Atlantic to the Pacific $\left(\Delta F_{a}\right.$, incorporated through additional terms in surface freshwater fluxes).

By varying the value of each parameter by small increments across a wide range, we are able to identify sharp transitions of equilibrium MOC strength in parameter space. For each parameter pair, the model is integrated for 4,000 years, by which point the THC is very close to equilibrium. Examining the simulation end states, we establish the parameter domains of two principal steady states: Conveyor Belt "On" (under high Atlantic-Pacific moisture exchange, low moisture diffusivity) and "Off" (under low Atlantic-Pacific moisture exchange, high moisture diffusivity). Two further intermediate steady states emerge in extreme regions of 
parameter space (high Atlantic-Pacific moisture exchange, high moisture diffusivity; low Atlantic-Pacific moisture exchange, low moisture diffusivity), characterised by weaker sinking in the North Atlantic. The existence of further THC steady states in C-GOLDSTEIN, qualitatively different from those identified here, cannot be discounted as we have only varied two parameters. However, the model does largely preclude high-latitude sinking (North of $60^{\circ} \mathrm{N}$ ), due to, in part, very coarse topography, and so perhaps lacks further northern sinking (and THC) states that may exist in the real world.

Nine selected final states from a first ensemble of simulations are used as the initial states for nine further ensembles. For each ensemble we obtain a unique MOC strength "surface" in 2-parameter space. Large differences between surfaces reveal the existence of multiple steady states in limited regions of parameter space, classically defined as arising through differences in the initial state. These regions broadly coincide, revealing a swathe of $\left(\Delta F_{a}, K_{q}\right)$ space characterised by more than one stable state of the THC.

We further reinterpret THC strength in 2-parameter space as the function of just one quantity, namely the net freshwater input to the Atlantic. The result of this analysis (Fig. 12) is suggestive of the classical overturning-freshwater flux hysteresis loop (e.g. Rahmstorf 1996). Both Conveyor "On" and "Off" modes of the THC can exist under virtually the same net freshwater flux, but in two distinct cases: for the same $\left(\Delta F_{a}, K_{q}\right)$ combination but different initial states; for different $\left(\Delta F_{a}, K_{q}\right)$ combinations. The former case corresponds to multiple equilibria. Strictly speaking, the "multiplicity" of THC equilibria identified here is generally two, both Conveyor "On" and "Off" states being stable. That two quite different THC states exist under the same net freshwater flux and the same $\left(\Delta F_{a}, K_{q}\right)$ combination (given different initial states) demonstrates that net freshwater flux is almost entirely controlled by $\Delta F_{a}$ and $K_{q}$, rather than the THC itself. The THC may exert more influence on this net freshwater flux in the real world (and in models with a dynamic atmosphere), as the low-latitude atmospheric circulation (and the Atlantic-Pacific moisture flux) is strongly coupled to tropical sea surface temperatures (Latif 2001).

The limited number of THC equilibria found here-a maximum of four states (Conveyor "On", Conveyor "Off", weak inter-hemispheric and weak northern-confined) in a limited $\Delta F_{a}$-range at high $K_{q}$ (see Fig. 9) - contrasts with the many equilibria suggested by previous studies (Lenderink and Haarsma 1994; Rahmstorf 1995a, b). We note that a larger number of THC equilibria in C-GOLDSTEIN have been found by using more elaborate methods to vary the initial conditions. JD Annan and JC Hargreaves (personal communications, 30/01/03) found 12 steady states for fixed parameter combinations. Most of these steady states were, however, characterised by very slightly different convection patterns, and not by significantly different circulation states. Present results support the suggestion that the multiple equilibria in some ocean models may be a side effect of convective adjustment, rather than a real physical property of thermohaline flows (Vellinga 1998). Ocean-atmosphere feedbacks are probably also important. Rahmstorf (1995) reports that multiple equilibria are more readily found in an ocean GCM under mixed boundary conditions, compared with the same GCM coupled to a simple energy-balance model (in the coupled model " $\ldots$ the overturning rate is very robust, apparently regulated by a negative thermal feedback").

Where both Conveyor "On" and "Off" states are stable under identical $\left(\Delta F_{a}, K_{q}\right)$, the model THC is particularly sensitive to freshwater forcing. To demonstrate this sensitivity, we add small $(0.1 \mathrm{~Sv})$ freshwater flux anomalies in the Atlantic zone $50-70^{\circ} \mathrm{N}$ over durations in the range $10-1,000$ years, initializing the model in one instance of the bistable "Conveyor On" state. A threshold is identified in terms of duration (to the nearest year). Under a minimum 88 years of additional freshwater forcing, the THC irreversibly collapses to the "Conveyor Off" state.

Once collapsed, the THC remains in this state due to the dominance of one or more positive feedbacks (Marotzke 1996). In a similar series of meltwater experiments with a coupled ocean-atmosphere GCM (the Hamburg LSG ocean model coupled to the ECHAM3 atmospheric model), Schiller et al. (1997) identified four major feedbacks influencing the recovery of a collapsed Atlantic THC: two (positive) feedbacks which maintain the collapsed state and two opposing (negative) feedbacks which aid recovery. The positive feedbacks are identified as reduced poleward salt advection and increased poleward atmospheric vapour transport, both maintaining low surface salinity in the northern sinking region.

Here we briefly consider those positive feedbacks which may account for bistablity of the THC in CGOLDSTEIN. Since advection itself does not alter ocean salinity, salt advection is impossible to separate from the very circulation that supports it. In this respect, it not clear that salt advection is a feedback as such. The poleward moisture flux feedback is, however, unambiguous. Figure 17a shows the net supply of freshwater to the Atlantic sector due to zonally integrated surface fluxes, for the extreme "On" and "Off" states shown in Fig. 10a (similar results are obtained for the pair of states in Fig. 10b, not shown here). The surface fluxes comprise freshwater gain/loss in the tropics/extratropics, and further freshwater gain in mid and high latitudes, as broadly evident in Fig. 3. Differences in the net surface freshwater flux between the Conveyor "On" and "Off" states are small. Integrating net freshwater flux over the sinking region $90^{\circ} \mathrm{W}-20^{\circ} \mathrm{E}, 40-60^{\circ} \mathrm{N}$, freshwater gain in the Conveyor "On" case is $0.021 \mathrm{~Sv}$, while in the Conveyor "Off" case this increases slightly to $0.033 \mathrm{~Sv}$. The extra freshwater gain ("Off" minus "On") in this key region is only $0.012 \mathrm{~Sv}$. This extra freshening amounts 

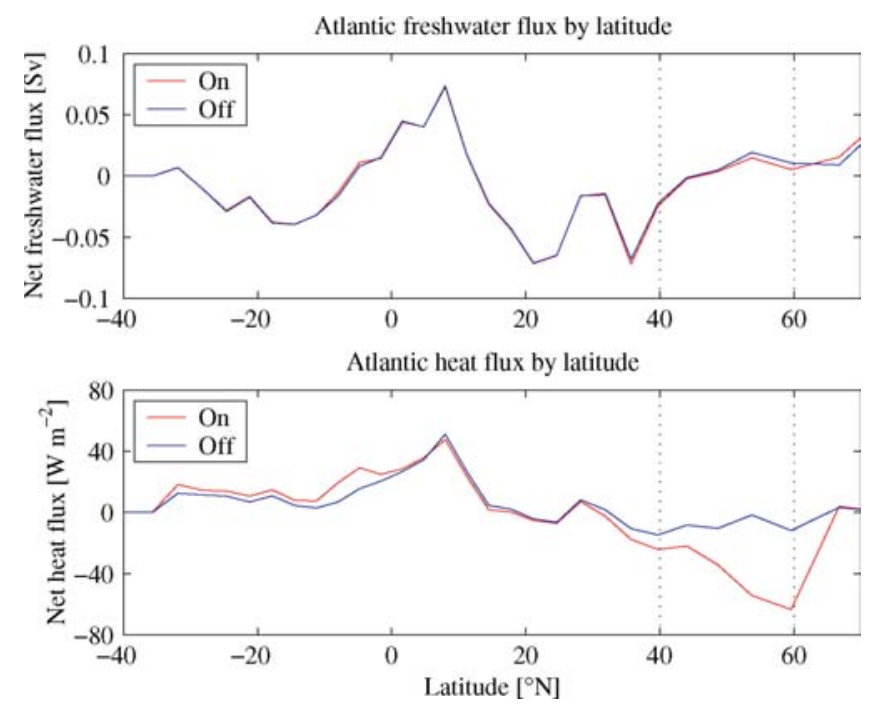

Fig. 17 Net freshwater (a, top) and heat (b, bottom) fluxes across the Atlantic basin for the pair of Conveyor "On"/"Off" simulations in Fig. 10a. The dotted lines mark the $40-60^{\circ} \mathrm{N}$ deep sinking region

to a positive feedback, suppressing overturning in the Conveyor "Off" state. Our other results have shown that small changes in net freshwater flux can have a large impact close to the threshold between "On" and "Off" states. However, a series of fixed flux experiments (see Fig. 14) suggest that the dominant positive feedback in C-GOLDSTEIN is reduced surface heat flux under a collapsed Conveyor, due to the absence of convection. To illustrate this, and for comparison with the corresponding freshwater fluxes, Fig. 17b shows the zonally averaged heat flux for the Atlantic sector. As is clear from the plot, surface cooling is considerably reduced in the Conveyor "Off" state. Integrated over the zone 40$60^{\circ} \mathrm{N}$, net cooling is $0.483 \mathrm{PW}$ in the Conveyor "On" state and $0.130 \mathrm{PW}$ in the Conveyor "Off" state. We therefore conclude that both net surface freshwater gain and reduced surface cooling (associated with stalled convection) act together as positive feedbacks in C-GOLDSTEIN, but that the dominant feedback involves reduced surface cooling.

In a further series of forced experiments, we apply the freshwater forcing for 250 years, for a range of initial states and $\left(\Delta F_{a}, K_{q}\right)$ pairs in and around the bistable region of parameter space. In most cases, the collapsed THC recovers at some point over the 4,000-year forced experiment due to dominant negative feedbacks. The two negative feedbacks identified by Schiller et al. (1997) act to increase surface density through increases in surface ocean heat loss and the Ekman suction of relatively salty deep water, due to deepening of the North Atlantic atmospheric trough and intensified cyclonic circulation in the subpolar gyre. Without a dynamic atmosphere, THC recovery in C-GOLDSTEIN must be due to a surface cooling feedback. However, the local (northern) atmospheric cooling associated with a collapsed THC (see Fig. 11) is somewhat weaker than that typical of
THC collapse in fully coupled GCMs (e.g. Fig. 12 of Schiller et al. 1997), probably due to heavy parameterisation of atmospheric transports in the EMBM. This may explain why THC collapse is more commonplace in climate models with simple atmospheric modules (such as the EMBM), as compared to those which incorporate atmospheric GCMs of full complexity: in the bistable regime of models such as C-GOLDSTEIN, atmospheric cooling is limited, and the associated (negative) feedback too weak, to stabilise a collapsing Conveyor. Indeed, as we have already seen, irreversible THC collapse in CGOLDSTEIN (in the bistable regime) is promoted by the positive feedbacks associated with reduced surface heat loss (due to suppressed convection). Only in the monostable regime does a collapsed THC recover through the negative cooling feedback, due to atmospheric cooling.

By determining and mapping the steady states and multiple equilibria of the THC, in unprecedented detail even for a model of intermediate complexity, we have demonstrated a powerful new methodology for exploring the behaviour and sensitivity of such a model. Under threshold values for two key parameters, we have confirmed the possibility of rapid and irreversible THC collapse under small freshwater perturbations of limited duration. One other study with an efficient climate model has shown that irreversible THC collapse can occur under strong transient $\mathrm{CO}_{2}$ forcing if North Atlantic freshwater sources of similar strength to ours (order $0.1 \mathrm{~Sv}$ ) arise as a parameterised feedback in response to northern hemisphere warming (Rahmstorf and Ganopolski 1999). Our sensitivity experiments are more idealized, in that the forcing only comprises an additional freshwater source. Along with Greenland meltwater fluxes the enhanced warming at high latitudes predicted under $\mathrm{CO}_{2}$ rise, and any associated positive feedback on freshwater supply to the Atlantic basin, could further increase the likelihood of THC collapse.

In the parameter space under consideration here, the model most closely resembles present-day climate (in terms of North Atlantic air temperature, Arctic sea ice cover, Atlantic net freshwater flux, MOC strength) in the monostable Conveyor "On" region of parameter space. The results further suggest that future irreversible collapse of the THC under weak external forcing (e.g. global warming, melting ice caps) may only become possible through considerable changes in the hydrological cycle, namely intensification globally and/or reduced Atlantic moisture export. However, it is not yet possible, with this or any other extant climate model, to determine with useful precision how close the present-day ocean circulation may be to the sensitive region where multiple equilibria are possible, although the palaeo-climate record suggests that it is within the range characterised by glacial-interglacial transitions (which are associated with $\mathrm{CO}_{2}$ variations smaller than those already generated by anthropogenic forcing). Moreover, since we are at present not able to characterise the probability distributions of the controlling parameters, it is not yet 
possible to interpret our results in terms of the probability of THC collapse under enhanced freshwater forcing. Our results indicate, however, that rather extensive parameter space mapping is very helpful in exploring the full range of model behaviour, which can be quite diverse, and that results from small numbers of simulations with models should be interpreted with considerable caution. Further developments of models which are efficient enough to be used for thorough sensitivity testing and parameter exploration, and methods for so exercising them, are likely to reveal new insights and increase confidence in the generality and validity of their behaviour.

Acknowledgements This work is an output of the GENIE project of the UK Natural Environment Research Council (NERC) e-Science thematic programme (NER/T/S/2002/00217). M.Y. Gulamali, T.M. Lenton and A. Yool are funded by GENIE. R. Marsh is supported under the NERC Core Strategic Programme, "Ocean Variability and Climate". N.R. Edwards is supported by the National Centres of Competence in Research (Climate), Switzerland. David Baker and $\mathrm{Oz}$ Parchment (University of Southampton) provided technical assistance by helping to achieve the first flocking of Condor pools through firewalls between UK universities. John Darlington (Imperial College) helped organise and facilitate GENIE experiments. The authors are especially grateful to Jochem Marotzke, for helpful guidance during early discussions of these experiments, and to Paul Valdes, whose original idea formed the basis of this work. We are also grateful to three anonymous referees whose suggestions considerably improved the final form of this manuscript.

\section{Appendix}

The computational infrastructure exploited in this paper represents a new paradigm in computing known as Grid computing (Foster et al. 2001). The resources exploited herein have been made available by their host institutions as part of the GENIE project, which aims to develop and deploy a Grid-based, modular, distributed and scalable earth system model for long-term and palaeo-climate studies to the environmental sciences community, as part of the UK's e-Science programme (i.e. see http://www.rcuk.ac.uk/escience/). In this appendix we briefly describe this technology with respect to the analyses presented in this paper.

The independent nature of each of the 961 individual model runs of C-GOLDSTEIN, in a single ensemble experiment, implies that there is no communication between runs and thus all runs can be executed simultaneously. We found Condor (Thain et al. 2003) to be an efficient and powerful computational resource that allowed us to perform our ensemble experiments in a fraction of the time of sequentially executed experiments.

Condor is a specialized workload management system for computationally intensive jobs that can be configured to utilise spare CPU cycles on idle workstations. It can provide additional features for distributed computing jobs including automatic checkpointing, automatic job migration and automatic file transfer (e.g. see Litzkow et al. 1997). By making use of these features we were able to reduce the net execution time of a single ensemble experiment from the calculated 160 days (see Sect. 3) to approximately 3 days.

Our Condor resource consisted of existing Condor "pools" residing at the London e-Science Centre (http:// www.lesc.ic.ac.uk/), the Department of Computing at Imperial College London (http://www.doc.ic.ac.uk/), and the Southampton Regional e-Science Centre (http:// www.e-science.soton.ac.uk/). These were combined into a single computing resource using the "flocking" features within Condor (e.g. see Epema et al. 1996). Port ranges, specified by the Condor and firewall administrators at the institutions above, were designated and utilised in order to overcome institutional firewalls. The flocked Condor pool was composed of approximately 200 Linux and Solaris based workstations at peak times (i.e. when the host institutions allowed these workstations to be available, and CPU activity on them was low).

In order to run the C-GOLDSTEIN model on the flocked Condor pool it was compiled from source on both the Linux and Solaris platforms, with the standard Condor libraries. This allowed Condor to use additional features during runtime such as those described above. In particular, by utilising the Condor File Transfer Mechanism in our Condor submission scripts we did not have to ensure that each of our Condor pools in the flocked Condor pool had access to a shared file space.

In addition to this computational resource, a prototype, web-based portal was also employed to manage the ensemble experiments. The portal automated the task of creating the necessary files for an ensemble experiment (amounting to the creation of 961 individual input files), as well as allowing one to submit experiments to the Condor pool and subsequently monitor their progress. The results of previously completed experiments could also be retrieved through the portal.

The portal was accessed through a certificate-based authentication and authorisation mechanism, and used Apache Tomcat servlets technology (e.g. see Brittain and Darwin 2003) to interface the web server with the underlying Condor resource and file system, providing a systematic way of managing experiments.

To summarise, the facilities described above raised the level of abstraction of the science presented herein, allowing us to rapidly develop and execute a succession of ensemble experiments, and affording us greater time to analyse and discuss the results of the experiments, without burdening us with the technicalities of the resources involved. Further details about the technological aspect of the experiments presented here may be found in Gulamali et al. (2003).

\section{References}

Annan JD, Hargreaves JC, Edwards NR, Marsh R (2004) Parameter estimation in an intermediate complexity earth system model using an ensemble Kalman filter. Ocean Model (in press) 
Brittain J, Darwin IF (2003) Tomcat: the definitive guide. O'Reilly and Associates, UK, p 332

Broecker WS (1998) Paleocean circulation during the last deglaciation: a bipolar seesaw? Paleoceanography 13:119-121

Cubasch U, Meehl GA, Boer GJ, Stouffer RJ, Dix M, Noda A, Senior CA, Raper S, Yap KS (2001) Projections of future climate change. Climate change 2001: the scientific basis. In: Houghton JT, Ding Y, Griggs DJ, Noguer M, Linden PJvd, Dai X, Maskell K, Johnson CA (eds) Contribution of working group I to the third assessment report of the intergovernmental panel on climate change. Cambridge University Press, London, pp 525-582

Curry R, Dickson RR, Yashayaev I (2003) A change in the freshwater balance of the Atlantic Ocean over the past four decades. Nature 426:826-829

Delworth T, Manabe S, Stouffer RJ (1993) Interdecadal variations of the thermohaline circulation in a coupled ocean-atmosphere model. J Climate 6:1993-2011

Edwards NR, Marsh R (2004) An efficient climate model with three-dimensional ocean dynamics. Clim Dyn (submitted)

Edwards NR, Shepherd JG (2002) Bifurcations of the thermohaline circulation in a simplified three-dimensional model of the world ocean and the effects of interbasin connectivity. Clim Dyn $19: 31-42$

Edwards NR, Willmott AJ, Killworth PD (1998) On the role of topography and wind stress on the stability of the thermohaline circulation. J Phys Oceanogr 28:756-778

Epema DHJ, Livny M, van Dantzig R, Evers X and Pruyne J (1996) A worldwide flock of Condors: load sharing among workstation clusters. Future Gener Comput Syst 12:53-65

Foster I, Kesselman C, Tuecke S (2001) The anatomy of the grid: enabling scalable virtual organizations. Int $\mathbf{J}$ High Perform Comput Appl 15:200-222

Gulamali MY, Lenton TM, Yool A, Price AR, Marsh RJ, Edwards NR, Valdes PJ, Watson JL, Cox SJ, Krznaric M, Newhouse S, Darlington J (2003) GENIE: delivering e-Science to the environmental scientist, Proceedings of the UK e-Science All Hands Meeting 2003, pp 145-152

Huybrechts P, DeWolde J (1999) The dynamic response of the Greenland and Antarctic ice sheets to multiple-century climatic warming. J Climate 12:2169-2188

Latif M (2001) Tropical Pacific/Atlantic Ocean interactions at multi-decadal timescales. Geophys Res Lett 28:529-542

Latif M, Roeckner E, Mikolajewicz U, Voss R (2000) Tropical stabilisation of the thermohaline circulation in a greenhouse warming simulation. J Climate 13:1809-1813

Lenderink G, Haarsma R (1994) Variability and multiple equilibria of the thermohaline circulation associated with deep water formation. J Phys Oceanogr 24:1480-1493

Litzkow M, Tannenbaum T, Bashley J, Livny M (1997) Checkpoint and migration of UNIX processes in the Condor distributed processing system. Technical report 1346, Computer Sciences Department, University of Wisconsin-Madison, Madison

Manabe S, Stouffer RJ (1997) Coupled ocean-atmosphere model response to freshwater input: comparison to Younger Dryas event. Paleoceanography 12:321-336
Marotzke J (1996) Analysis of thermohaline feedbacks. NATO ASI series I44:334-378

Oort AH (1983) Global atmospheric circulation statistics, 19581973. NOAA Professional Paper 14

Rahmstorf S (1994) Rapid climate transitions in a coupled oceanatmosphere model. Nature 372:82-85

Rahmstorf S (1995a) Multiple convection patterns and thermohaline flow in an idealized OGCM. J Climate 8:3028-3039

Rahmstorf S (1995b) Bifurcations of the Atlantic thermohaline circulation in response to changes in the hydrological cycle. Nature 378:145-149

Rahmstorf S (1996) On the freshwater forcing and transport of the Atlantic thermohaline circulation. Clim Dyn 12:799-811

Rahmstorf S (2000) The thermohaline ocean circulation-a system with dangerous thresholds. Clim Change 46:247-256

Rahmstorf S, Ganopolski A (1999) Long-term global warming scenarios computed with an efficient coupled climate model Clim Change 43:353-367

Schiller A, Mikolajewicz U, Voss R (1997) The stability of the North Atlantic thermohaline circulation in a coupled oceanatmosphere general circulation model. Clim Dyn 13:325-347

Schmittner A, Appenzeller C, Stocker TF (2000) Enhanced Atlantic freshwater export during El Nino. Geophys Res Lett 27:1163-1166

Stocker TF (1998) The seesaw effect. Science 282:61-62

Stouffer RJ, Dixon KW, Gregory JM, Spelman MJ, Hurlin W (2004) A coupled model intercomparison of the climate response to freshwater input in the north Atlantic Ocean. Geophys Res Abstr 6:1254

Thain D, Tannenbaum T, Livny M (2003) Condor and the grid. In: Berman F, Hey AJG, Fox G (eds) Grid computing: making the global infrastructure a reality.Wiley, New York, pp 299-335

Thorpe RB, Gregory JM, Johns TC, Wood RA, Mitchell JFB (2001) Mechanisms determining the Atlantic thermohaline circulation response to greenhouse gas forcing in a non-flux-adjusted coupled climate model. J Climate 14:3102-3116

Vellinga M (1998) Multiple equilibria in ocean models as a side effect of convective adjustment. J Phys Oceanogr 28:621-633

Wang H, Birchfield GE (1992) An energy-salinity balance climate model: water vapor transport as a cause of changes in the global thermohaline circulation. J Geophys Res 97:2335-2346

Weaver AJ, Eby M, Wiebe EC, Bitz CM, Duffy PB, Ewen TL, Fanning AF, Holland MM, MacFadyen A, Matthews HD, Meissner KJ, Saenko O, Schmittner A, Wang HX, Yoshimori M (2001) The UVic Earth System Climate Model: model description, climatology, and applications to past, present and future climates. Atmos Ocean 39:361-428

Wood RA, Keen AB, Mitchell JFB, Gregory JM (1999) Changing spatial structure of the thermohaline circulation in response to atmospheric $\mathrm{CO}_{2}$ forcing in a climate model. Nature 399:572575

Yang F, Kumar A, Schlesinger ME, Wang W (2003) Intensity of hydrological cycles in warmer climates. J Climate 16:2419-2423

Zaucker F, Broecker WS (1992) The influence of atmospheric moisture transport on the fresh water balance of the Atlantic drainage basin: general circulation model simulations and observations. J Geophys Res 97:2765-2773 